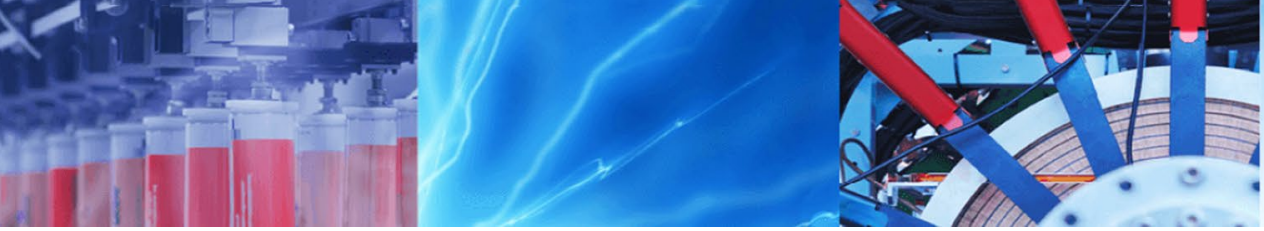

Research Article

\title{
Three methods of estimating the power of maximum temperature in TM-ET estimation equation
}

\author{
Berhanu Mengistu' ${ }^{1} \cdot$ Gelana Amente $^{1}$
}

(c) Springer Nature Switzerland AG 2019

\begin{abstract}
The use of FAO56-PM is still the preferred method for the estimation of evapotranspiration (ET) regardless of locations. But in places where data that satisfy all the meteorological variables of PM equation are non-existent or missing, the use of either temperature or radiation-based methods is the alternative option, since both radiation and temperature are the main drivers of ET. From the latter two, temperature-based ET estimation methods are still the simplest ones to use. However, there are challenges since some of the parameters used in the temperature-based equations are location dependent. Such location dependence is due to variability in terms of latitude, altitude and other geo-location parameters. Therefore, local calibration of temperature-based methods is necessary to get better estimates of ET. In this study, one temperature-based ET estimation method known as Temesgen-Melesse's (TM) method was assessed in relation to the PM equation using data of ten Class I meteorological stations in Ethiopia. In the study, three different techniques were tested to find location-dependent maximum temperature power (' $n$ ') used in TM equation (i.e., to calibrate the method). The first two techniques involve calibration using PM data. In the first case, monthly averaged data that span from 1 to 5 years were used (as five data sets of 12,24, 36, 48 and 60 months). In the second case, daily values that span from 10 to 30 days were used in three groups of 10-, 20-, and 30-day data sets. In the third technique, an attempt was made to estimate ' $n$ ' from the location latitude, altitude and average of the monthly averaged maximum temperature $\left(T_{m x}\right)$. The results obtained from each technique are given as follows. Calibration from the monthly averaged data gave good ' $n$ ' values for all the stations with $R^{2}$ values ranging from 0.80 to 0.92 . There were no differences in the number of data points $(12,24,36,48$ and 60 months) used, which means data points of 12 months are sufficient for the calibration. Calibration using the daily data gave satisfactory ' $n$ ' results for all the stations tested, though the statistical parameters and performance tests did not give results that are comparable to the monthly averaged values. The results were nearly the same for 10-, 20-, or 20-day data points, which means any one of them can be used for calibration purposes. Estimation of ' $n$ ' from latitude, altitude and $T_{m x}$ gave results that are comparable to the ones with ' $n$ ' calibrated. The percent differences between the ' $n$ ' calibrated using data of 131 months and the ' $n$ ' values obtained from monthly data and daily data calibrations are less than $0.16 \%$ and $0.5 \%$, respectively. The calculated ' $n$ ' showed a percent difference of less than $1.1 \%$. Using calculated ' $n$ ' is better than performing calibration using daily data. It can also be considered as option when at least 1-year PM data are not available for calibration.
\end{abstract}

Keywords FAO PM equation · Potential evapotranspiration · Temesgen-Melesse's equation · Temperature-based ET

Berhanu Mengistu, aquamengistu@gmail.com $\mid{ }^{1}$ College of Natural and Computational Sciences, Haramaya University, Dire Dawa, Ethiopia.

SN Applied Sciences (2019) 1:1403 | https://doi.org/10.1007/s42452-019-1461-9

Received: 27 July 2019 / Accepted: 7 October 2019 / Published online: 15 October 2019

SN Applied Sciences

a SPRINGer nature journal 


\section{Introduction}

The use of FAO56-PM equation is the recommended method to estimate potential evapotranspiration of a given location. The equation is physically based [1] and therefore provides consistent $\mathrm{ET}$ in many regions and climates without any need to estimate additional parameters $[6,11]$. But it requires many meteorological variables such as input of temperature, wind speed, relative humidity and radiation that limit its widespread use [19]. The number of stations where these variables are recorded hourly or even daily is limited in many areas of the globe [1]. There are many meteorological stations that do not record meteorological variables required for PM equation [30], and hence, input data are not always available in some regions. Extended missing data points for some of the variables used in the PM equation, malfunction of instrument, instrument error, the level of experience of the instrument reader, careless data transfer from secondary storage [23] or even the limited length of data duration are some of the reasons that limit the use of PM equation for a study that require long years of data. There are also problems of quality and integrity of meteorological data such as wind speed, sunshine hour and humidity $[23,26]$. An alternative option for such study is the use of ET estimation methods that are less demanding in terms of input data [1]. When data are not available, the use of a simpler empirical equation is recommended [30]. This is necessary, for instance, when there is a need to undertake the study of climate change, drought patterns, etc., which in some cases require data of 30 years or more. In most developing countries, it may not always be possible to find data that spans this much duration for a large number of locations of interest. If data are available for all the variables of PM equation even for limited duration, the ET calculated from the PM equation can be used as a reference for comparison or for calibration purposes $[3,11]$.

The simpler empirical equations are either temperature-based, radiation-based or combinations of the two. Temperature-based ET estimation methods are the favorable options due to their limited requirement in terms of input variables $[5,30]$. Temperature is easily measured and more accurately than the other variables, and the data are always available in almost all meteorological stations and for a longer time [23]. For instance, Pandey et al. [21] and Peng et al. [22] mention the capability of temperature-based methods in demonstrating potential evapotranspiration with reasonable accuracy. Oudin et al. [20] obtained temperature-based equations to be more suitable than even the FAO56-PM equation when the data duration is very short (30 days or less).
From among the temperature-based methods, the one developed by Temesgen and Melesse [25] is an option and has been applied on data of several meteorological stations in Ethiopia. But this method has limitation since the parameters used in the equation (especially, the power of the monthly averaged maximum temperature, ' $n$ ') vary with location and require calibration.

This study tries to propose three ways to improve the original constant the authors have proposed for the monthly averaged maximum temperature $(n=2.5)$ and to recalibrate this parameter. Aguilar and Polo [1], Bogawski and Bednorz [7], Almorox et al. [5], Dinpashoh [9], Neto et al. [19], Pandey et al. [21] and Peng et al. [22], for instance, mention the importance of regional calibration to eliminate the problem of over or underestimation of ET by different methods and to enhance performance and accuracy for specific climates. The calibration process requires limited data that satisfy PM equation. For stations that have data that span few years, it is possible to consider monthly averaged data for calibration. In some cases, the data available may only be for a couple of days or as an alternative, measurements could also be taken for few days, and such daily values may be used for calibration. The workability of the second method can be tested not necessarily by taking measurements, but rather, by using existing daily data of few stations. Nevertheless, it is not clearly known how many of the monthly averaged or the daily data points may be sufficient for calibration. Hence, this study tries to find first the optimum number of monthly averaged data points required for calibration that uses the monthly averaged values and second, to do the same for the daily values.

There are also stations that do not have data for all the variables required in the PM equation. For such locations calibration is not an option, and what remains is either to use the original constant proposed by the authors (i.e., [25]), $n=2.5$ or find a method to estimate the power of the maximum temperature. With regard to this, a third option was devised to estimate the power of the monthly averaged maximum temperature from some sort of locationdependent geographical parameters. In other words, it is necessary to associate ' $n$ ' with location-dependent quantities. In this case, it is imperative to know which locationdependent quantities are used and how they are related to 'n.' Not only that, the results obtained must also be tested (validated) using data from other stations.

In this study, these three alternatives were tested using data of five Class I meteorological stations for the first two (calibration of monthly and daily values) and data of eight stations of the same standard for the last alternative (estimation of ' $n$ ' from location-dependent geographical parameters). Besides, two independent stations were used to validate the result of the third option. 


\section{Materials and methods}

\subsection{About the stations}

In this study, 1-5-year data of five Class I meteorological stations in Ethiopia were selected for maximum temperature power calibration using monthly (Cal.1) and daily (Cal.2) data. The stations were: Addis Ababa, Debre Birhan, Desse, Mekele and Metehara stations. In addition to the five stations, data of three more stations (Addet, Bahir Dar and Dangla) were used to estimate ' $n$ ' ('n'est.) from latitude, altitude and the averaged maximum temperature. In addition, two more stations (Zeway and Hawassa) were used for model testing. Data of Zeway station were used to test the monthly calibrated ' $n$ ' and that of Hawassa to test the daily-calibrated 'n.' Geographical and meteorological information of these stations is given in Table 1.

\subsection{Study methods}

In this study, three types of tests were done. In the first case, tests were done using monthly averaged data sets of five meteorological stations (Addis Ababa, Debre Birhan, Desse, Mekele and Metehara) to calibrate ' $n$.' For the second option, daily data sets of the same stations were used for calibration purposes. For the third option, data of three more stations (Addet, Bahir Dar and Dangla) were used in addition to the five stations mentioned before, to estimate ' $n$ ' from location-dependent parameters.

The first test was for those stations that have limitedyear data that satisfy the PM equation. The monthly averaged data of maximum temperature and ET-PM data were grouped into five categories of 1-, 2-, 3-, 4- and 5-year or 12 (1995)-, 24 (1995 and 1996)-, 36 (1995-1997)-, 48 (1995-1998)- and 60 (1995-1999)-month data points and were compared. The PMET to be used for comparison was calculated using Eq. 1 as suggested by Allen et al. [4].

$\mathrm{ET}-\mathrm{PM}=\frac{0.408 \Delta\left(R_{n}-G\right)+\gamma \frac{900}{T+273} u_{2}\left(e_{\mathrm{s}}-e_{\mathrm{a}}\right)}{\Delta+\gamma\left(1+0.34 u_{2}\right)}$

$\mathrm{ET}_{\mathrm{PM}}$ is reference evapotranspiration $\left(\mathrm{mm} \mathrm{day}^{-1}\right) ; R_{n}$ is the net radiation at the crop surface $\left(\mathrm{MJ} \mathrm{m}^{-2}\right.$ day $\left.^{-1}\right) ; G$ is soil heat flux density $\left(\mathrm{MJ} \mathrm{m}^{-2}\right.$ day $\left.^{-1}\right)$, assumed to be zero on daily basis; $T\left({ }^{\circ} \mathrm{C}\right)$ is mean daily air temperature at 2-m height; $u_{2}$ is wind speed at $2-\mathrm{m}$ height $\left(\mathrm{m} \mathrm{s}^{-1}\right) ; e_{s}$ is saturation vapor pressure $(\mathrm{kPa}) ; \mathrm{e}_{\mathrm{a}}$ is actual vapor pressure $(\mathrm{kPa})$; $\mathrm{e}_{\mathrm{s}}-\mathrm{e}_{\mathrm{a}}$ is saturation vapor pressure deficit $(\mathrm{kPa}) ; \Delta$ is slope of vapor pressure curve $\left(\mathrm{kPa}^{\circ} \mathrm{C}^{-1}\right)$; and $\mathrm{g}$ is psychrometric constant $\left(\mathrm{kPa}^{\circ} \mathrm{C}^{-1}\right)$. Thereafter, the maximum temperature values were plotted against ET-PM values and custom curve-fitted using the modified ET-TM equation (Eq. 2), for each year, independently, using MATLAB R2018a software, and the $T_{m x}$ powers (' $n$ ' values) were calibrated for each location.

$\mathrm{ET}-\mathrm{TM}_{\mathrm{mod}}=\frac{T_{\mathrm{mx}}^{n}}{48 \bar{T}_{\mathrm{mx}}-330}$

The optimized ' $n$ ' is given the name ' $n_{\text {modopt. }}$ Then ET-PM of the 5 years was plotted against the five $\mathrm{ET}_{\mathrm{mo}} \mathrm{s}$ (represented in the figures as $\mathrm{ET}_{1}, \mathrm{ET}_{2}, \mathrm{ET}_{3}, \mathrm{ET}_{4}$ and $\mathrm{ET}_{5}$ ) on the same axes using Microsoft Excel. From the plots, the statistical parameters such as the slope (Eq. 3) and the coefficient of determination, $R^{2}$ (Eq. 4) were determined. In addition, to compare the performances of
Table 1 Information about the stations used for maximum temperature power calibration

\begin{tabular}{|c|c|c|c|c|c|c|c|c|c|c|}
\hline \multirow[t]{2}{*}{ Station } & \multicolumn{2}{|c|}{ Location } & \multirow[t]{2}{*}{ Altitude $(\mathrm{m})$} & \multicolumn{3}{|c|}{ Temperature $\left({ }^{\circ} \mathrm{C}\right)$} & \multicolumn{3}{|c|}{$\begin{array}{l}\text { 'n' calibration and } \\
\text { estimation }\end{array}$} & \multirow[t]{2}{*}{ Testing } \\
\hline & Lat. (N) & Long. (E) & & $T_{\text {mean }}$ & $T_{\mathrm{mx}}$ & $T_{\mathrm{mn}}$ & Cal. $1^{* *}$ & $\begin{array}{l}\text { Cal. } \\
2^{* * *}\end{array}$ & 'n' est. & \\
\hline Addis Ababa & $8.59^{\circ}$ & $38.48^{\circ}$ & 2386 & 17.1 & 23.8 & 10.3 & $\checkmark$ & $\checkmark$ & $\checkmark$ & \\
\hline Addet & $11.27^{\circ}$ & $37.49^{\circ}$ & 2179 & 17.6 & 25.6 & 9.7 & & & $\checkmark$ & \\
\hline Bahir Dar & $11.36^{\circ}$ & $37.24^{\circ}$ & 1800 & 18.2 & 25.6 & 10.8 & & & $\checkmark$ & \\
\hline Dangla & $11.25^{\circ}$ & $36.83^{\circ}$ & 2116 & 17.7 & 25.7 & 9.7 & & & $\checkmark$ & \\
\hline Debre Birhan & $9.38^{\circ}$ & $39.3^{\circ}$ & 2750 & 13.6 & 19.8 & 7.3 & $\checkmark$ & $\checkmark$ & $\checkmark$ & \\
\hline Desse & $11.07^{\circ}$ & $39.38^{\circ}$ & 2553 & 15.6 & 22.8 & 8.3 & $\checkmark$ & $\checkmark$ & $\checkmark$ & \\
\hline Mekele & $13.31^{\circ}$ & $39.28^{\circ}$ & 2000 & 20.1 & 26.8 & 13.3 & $\checkmark$ & $\checkmark$ & $\checkmark$ & \\
\hline Metehara & $8.51^{\circ}$ & $39.55^{\circ}$ & 944 & 22.6 & 27.8 & 17.3 & $\checkmark$ & $\checkmark$ & $\checkmark$ & \\
\hline Zeway & 7.56 & 38.42 & 1640 & 20.1 & 26.9 & 13.3 & & & & $\checkmark$ \\
\hline Hawassa & 6.62 & 38.31 & 1680 & $21.4^{*}$ & $27.1^{*}$ & $15.6^{*}$ & & & & $\checkmark$ \\
\hline
\end{tabular}

$T_{\text {mean }}=$ mean temperature; $T_{\mathrm{mx}}=$ maximum temperature; $T_{\mathrm{mn}}=$ minimum temperature; Cal. $1^{* *}={ }^{\prime} \mathrm{n}^{\prime}$ calibrated using monthly data of $1995-1999$; Cal. $2^{* * *}=' n$ ' calibrated using daily data; and ' $n$ ' est. =' $n$ ' estimated from latitude, altitude and $T_{\mathrm{mx}}{ }^{*}$ Hawassa data used are that of March 2017 
each of the data sets, performance test parameters were evaluated using the methods given in Sect. 2.2. Finally, the statistical parameters and performance test parameters were tabulated to select the data sets that give the best ' $\mathrm{n}_{\text {modopt }}$ '.

For the daily data sets test, again the five stations mentioned in the previous paragraph were used. Data of identical months were selected for all the five stations. In this case, however, only three data sets were considered. For the first test, only ten-day data points were used out of the total 30 data points. For the second test, the first twenty of the 30 data points were used. For the third, all of the 30-day data points were used. Thereafter, comparisons of performances of the three were made. The procedures followed were as mentioned in the previous paragraph, with the exception of the monthly averaged data replaced with the daily data values.

In the third case, it was necessary to take more meteorological stations to estimate ' $n$.'This was because of the curve fitting required for the estimation of ' $n$, and therefore, three more stations were considered in addition to the five stations used in the other methods. Data of Zeway and Hawassa stations were used for validation (using the daily and monthly averaged data points of Hawassa and Zeway, respectively). The list of abbreviations used in the equations, tables and figures are given in Table 2, for quick reference.

\subsection{Mathematical methods of evaluating the statistical parameters and performance tests}

The model tendencies, statistical parameters and performance tests are essential to check how the different methods perform. The linear relation between the predicator (ET-PM) and the predicted (the ET values evaluated using the monthly averaged and the daily data) with optimized ' $\mathrm{n}_{\text {modopt }}$ ' values was linearly fitted without intercepts as shown in Eq. 3.

$y^{*}=b^{*} x$

The slope $\left(b^{*}\right)$ is used as a test parameter. In order to know the method tendencies, it is necessary to use the slope of Eq. 3 with the $R^{2}$. The $R^{2}$ is the cross-correlation between $y^{\prime}$ and $x$ during regression, and it is given [2] as:

$R^{2}=\frac{\sum_{1}^{n}\left(y_{i}-\bar{y}\right)\left(y_{i}^{\prime}-\bar{y}^{\prime}\right)}{\left(\sum_{1}^{n}\left(y_{i}-\bar{y}\right)^{2} \sum_{1}^{n}\left(y_{i}^{\prime}-\bar{y}^{\prime}\right)^{2}\right)^{0.5}}$.

The ' $n$ ' in this case is the number of data considered, $y_{i}$ represents ET-PM value of the ith data, $y_{i}^{\prime}$ is regression estimated value of ET for the ith value, and $y$ and $\bar{y}^{\prime}$ are the average values of $y$ and $y^{\prime}$, respectively. A measure of $R^{2} \geq 0.7$ is required for the cross-correlation to be considered good [2]. When $R^{2}$ is considered together with the slope (b), $R^{2} \geq 0.7$ and $0.7 \leq b \leq 1.3$ are required to assure good condition and homogeneity of the correlation [4].

Table 2 List of abbreviations used in this study and their definitions

\begin{tabular}{|c|c|c|}
\hline Abbreviations & Equation & Definition \\
\hline ET-PM & Equation 1 & FAO56-PM ET estimation method \\
\hline ET-TM & $\mathrm{ET}-\mathrm{TM}=\frac{T_{\mathrm{mx}}^{2.5}}{48 T_{\mathrm{mx}}-330}$ & Temesgen-Melesse's ET estimation method with $n=2.5$ \\
\hline ET-TM mod & Equation 2 & $\begin{array}{l}\text { Modified Temesgen-Melesse's ET estimation method with ' } n \text { ' to be calibrated } \\
\left(n_{\text {modopt }}\right) \text { and } T_{m x} \text { replaced with } T_{m x}\end{array}$ \\
\hline $\mathrm{ET}_{\text {nclct }}$ & Equation 10 & $\begin{array}{l}\text { Modified Temesgen-Melesse's ET estimation method with 'n' calculated form } \\
\text { latitude, altitude and } T_{m x}\end{array}$ \\
\hline $\mathrm{ET}_{\mathrm{mo}}$ & & 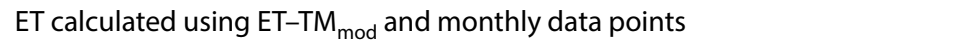 \\
\hline $\mathrm{ET}_{\mathrm{mo1}}$ & & ET calculated using ET-TM mod and 12-month data points \\
\hline $\mathrm{ET}_{\mathrm{mo2}}$ & & ET calculated using ET-TM mod and 24-month data points \\
\hline $\mathrm{ET}_{\mathrm{mo3}}$ & & ET calculated using ET-TM mod and 36-month data points \\
\hline $\mathrm{ET}_{\mathrm{mo4}}$ & & ET calculated using ET-TM mod and 48-month data points \\
\hline $\mathrm{ET}_{\mathrm{mo5}}$ & & ET calculated using ET-TM mod and 60-month data points \\
\hline $\mathrm{ET}_{\mathrm{d}}$ & & ET calculated using ET-TM mod and daily data points \\
\hline $\mathrm{ET}_{\mathrm{d} 1}$ & & ET calculated using ET-TM mod and 10-day data points \\
\hline $\mathrm{ET}_{\mathrm{d} 2}$ & & ET calculated using ET-TM $\mathrm{mod}_{\text {and }}$ anday data points \\
\hline $\mathrm{ET}_{\mathrm{d} 3}$ & & ET calculated using ET-TM mod and 30-day data points \\
\hline ET-TM mod $1_{1}$ & & 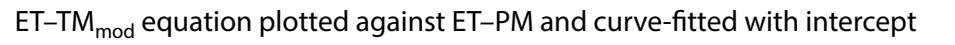 \\
\hline ET-TM $\bmod 2$ & & 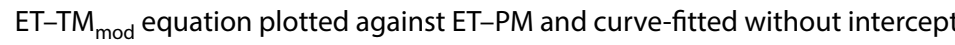 \\
\hline
\end{tabular}


The two parameters $\left(R^{2}\right.$ and $\left.\mathrm{b}^{*}\right)$ are regression or statistical parameters.

A one-to-one (1:1) slope line is the plot done between ET-PM and itself. This line is important to see whether the fitted (regression) line crosses it or not. The linear plot between the two quantities is required to be close to the 1:1 slope line without crossing it. If the regression line is parallel to the 1:1 slope line and is below the 1:1 line, it indicates underestimation (UE) of ET, and if above, overestimation (OE). When the two lines cross, it is indicative of the inadequacy of the method used.

Root mean square error (RMSE) is a measure of relative error, which is the error of the estimated method compared with the PM method. RMSE is given $[5,13,16]$ as:

$\mathrm{RMSE}=\left(\frac{\sum_{i}^{n}\left(\mathrm{ET}_{i}-\mathrm{ET}_{\mathrm{PMi}}\right)^{2}}{n}\right)^{0.5}$

$\mathrm{ET}_{i}$ is the ET estimated by one of the three methods, whereas $\mathrm{ET}_{\mathrm{PM} i}$ is the ET-PM. Both values are at the ith observation. RMSE ( $\mathrm{mm}$ day $^{-1}$ ) ranges from zero to infinity, but its value is considered good when it is closer to zero. It is indicator of the deviation in estimation [1] of ET. The corresponding relative RMSE (rRMSE) is the ratio of RMSE divided by the mean value of ET-PM, which when multiplied by $100 \%$ gives the relative error [11]. These values are given in parenthesis next to RMSE values in Tables 4 and 6. Although Neto et al. [19] suggest RMSE to be inappropriate parameter for evaluating model performance because of its change with variability of the error squares in the data, $[13,14]$ consider it more appropriate for large data compared to mean absolute error (MAE) [12]. Bogawski and Bednorz [7] even suggest using the ratio of RMSE with mean value of the reference data. In this case, it becomes a unitless number but is good for comparison when the considered data points are not of the same size.

Coefficient of efficiency (CE) is generally used as performance measure [24]. A measure of $C E$ is given as:

$\mathrm{CE}=1-\frac{\sum_{i}^{n}\left(\mathrm{ET}_{\mathrm{PM}}(i)-\mathrm{ET}(i)\right)^{2}}{\sum_{i}^{n}\left(\mathrm{ET}_{\mathrm{PM}}(i)-<\mathrm{ET}_{\mathrm{PM}}>\right)^{2}}$.

$\mathrm{EP}_{\mathrm{PM}}$ (i) and $\mathrm{ET}$ (i) are the PM and the parametric model values for the ith month (or ith day in the case of data values) and $(\bar{E} F)_{P M}$ are the PM evapotranspiration averaged over all the $n$ months ( $n$ days). The actual range of CE lies between minus infinity and one. According to Alblewi [2], if $0.75 \leq C E \leq 1$, the performance of the method is considered good, $0.36<C E<0.75$, satisfactory while $C E$ below 0.36 is considered poor. According to Maule et al. [17], when CE is below, zero is possible, and it means the method to be estimated is assumed to be a better predictor than the method that is supposed to predict it.

Coefficient of residual mean (CRM) is the way to compute residuals to check whether the method over or underestimates a given value. It is expressed [2] as:

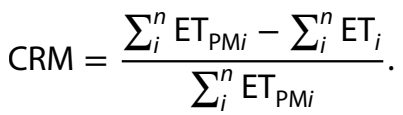

The variables are as explained in the previous cases. Even though CRM values range between minus infinity to plus infinity, what is actually considered is whether the value is above or below zero. Positive value indicates underestimation, while negative value indicates overestimation. A value close to zero implies close agreement between ET-PM and the estimated ET.

Mean percentage error (MPE) is used to measure the error between the predictor (ET-PM) and the predicted (the estimated methods). It is given as [10]:

MPE $=\frac{\sum_{i}^{n}\left[\frac{x-y}{x}\right]}{n}(100 \%)$.

The variable $x$ represents one of the estimated ET methods and $y$ represents ET-PM both observed during observation $i$, while $n$ is the total number of observations. Low MPE is preferred to show agreement between two models.

Coefficient of variation is defined as the ratio of the standard deviation (s) over the mean $(\bar{x})$. CV in percent form is given as,

$\mathrm{CV}(\%)=\frac{s}{\bar{x}}(100 \%)$.

Both $s$ and $\bar{x}$ are obtained from the data statistics. CV of less than $10 \%$ is preferred to make the data reliable. The $\mathrm{CV}$ may not mean much in this case other than showing the variations of the data points.

Prediction bound (PB) at $95 \%$ was included in the performance test to check whether the data points lie within, partially within or outside of the PB of the corresponding ET-PM. The assumption is based on the fact that when most of the data points are within the PB, the two methods are within $5 \%$ error from each other.

\section{Results and discussion}

\subsection{Determination of maximum temperatures ' $n_{\text {modopt }}$ 's from the monthly averaged data}

Following the procedure mentioned in Sect. 2.1, the average maximum temperatures and the corresponding 
optimized maximum temperature powers (' $\mathrm{n}_{\text {modopt }}$ 's) obtained by curve fitting are given in Table 3 . The ' $n_{\text {modopt }}$ 's shown in the last column of the table are the calculated values obtained using monthly data of 11 years.

As seen in the table, the difference in the ' $n_{\text {modopt }}$ ' obtained for all the data points are not different from each other at least up to two decimal places. The percent error is limited to $0.2 \%$ or less in all the cases. The same is also revealed by the standard deviations shown in the same table for each station. Besides, they are not also different from the ' $n$ ' values calibrated using the eleven-year monthly averaged data sets of the stations. But in order

Table 3 Maximum temperature power optimization using different numbers of monthly data sets

\begin{tabular}{|c|c|c|c|c|c|c|c|}
\hline Station & ET code & Data points & Average $T_{\mathrm{mx}}\left({ }^{\circ} \mathrm{C}\right)$ & $' n_{\text {modopt }}$ & Percent error & $R^{2}$ & ' $\mathrm{n}_{\text {modopt }}$ '11-year \\
\hline \multirow[t]{5}{*}{ Addis Ababa } & $\mathrm{ET}_{\mathrm{mo1}}$ & 12 & 23.72 & 2.498 & 0.12 & 0.7958 & \multirow[t]{8}{*}{2.495} \\
\hline & $\mathrm{ET}_{\mathrm{mo2}}$ & 24 & 23.57 & 2.494 & -0.04 & 0.7554 & \\
\hline & $\mathrm{ET}_{\mathrm{mo3}}$ & 36 & 23.75 & 2.498 & 0.12 & 0.7321 & \\
\hline & $\mathrm{ET}_{\mathrm{mo4}}$ & 48 & 23.77 & 2.495 & 0.00 & 0.6915 & \\
\hline & $\mathrm{ET}_{\mathrm{mo5}}$ & 60 & 23.81 & 2.496 & 0.04 & 0.7580 & \\
\hline Mean & & & 23.72 & 2.496 & & & \\
\hline Stdev. & & & 0.09 & 0.002 & & & \\
\hline CV (\%) & & & 0.39 & 0.072 & & & \\
\hline \multirow[t]{5}{*}{ Debre Birhan } & $\mathrm{ET}_{\mathrm{mo} 1}$ & 12 & 19.72 & 2.541 & 0.04 & 0.8793 & \multirow[t]{8}{*}{2.540} \\
\hline & $\mathrm{ET}_{\mathrm{mo2}}$ & 24 & 19.57 & 2.535 & -0.20 & 0.8491 & \\
\hline & $\mathrm{ET}_{\mathrm{mo3}}$ & 36 & 19.75 & 2.541 & 0.04 & 0.8177 & \\
\hline & $\mathrm{ET}_{\mathrm{mo4}}$ & 48 & 19.77 & 2.537 & -0.12 & 0.7483 & \\
\hline & $\mathrm{ET}_{\mathrm{mo5}}$ & 60 & 19.81 & 2.540 & 0.00 & 0.8133 & \\
\hline Mean & & & 19.72 & 2.539 & & & \\
\hline Stdev. & & & 0.09 & 0.003 & & & \\
\hline CV (\%) & & & 0.47 & 0.106 & & & \\
\hline \multirow[t]{5}{*}{ Desse } & $\mathrm{ET}_{\mathrm{mo} 1}$ & 12 & 22.72 & 2.526 & 0.08 & 0.6616 & \multirow[t]{8}{*}{2.524} \\
\hline & $\mathrm{ET}_{\mathrm{mo2}}$ & 24 & 22.57 & 2.522 & -0.08 & 0.6168 & \\
\hline & $\mathrm{ET}_{\mathrm{mo3}}$ & 36 & 22.75 & 2.526 & 0.08 & 0.6521 & \\
\hline & $\mathrm{ET}_{\mathrm{mo4}}$ & 48 & 22.77 & 2.524 & 0.00 & 0.6251 & \\
\hline & $\mathrm{ET}_{\mathrm{mo5}}$ & 60 & 22.81 & 2.525 & 0.04 & 0.7068 & \\
\hline Mean & & & 22.72 & 2.525 & & & \\
\hline Stdev. & & & 0.09 & 0.002 & & & \\
\hline CV (\%) & & & 0.41 & 0.066 & & & \\
\hline \multirow[t]{5}{*}{ Mekele } & $\mathrm{ET}_{\mathrm{mo} 1}$ & 12 & 26.72 & 2.511 & 0.00 & 0.7958 & \multirow[t]{8}{*}{2.511} \\
\hline & $\mathrm{ET}_{\mathrm{mo2}}$ & 24 & 26.57 & 2.506 & -0.20 & 0.7554 & \\
\hline & $\mathrm{ET}_{\mathrm{mo} 3}$ & 36 & 26.75 & 2.511 & 0.00 & 0.7321 & \\
\hline & $\mathrm{ET}_{\mathrm{mo4}}$ & 48 & 26.77 & 2.509 & -0.08 & 0.6915 & \\
\hline & $\mathrm{ET}_{\mathrm{mo5}}$ & 60 & 26.81 & 2.511 & 0.00 & 0.7580 & \\
\hline Mean & & & 26.72 & 2.510 & & & \\
\hline Stdev. & & & 0.09 & 0.002 & & & \\
\hline CV (\%) & & & 0.34 & 0.087 & & & \\
\hline \multirow[t]{5}{*}{ Metehara } & $\mathrm{ET}_{\mathrm{mo1}}$ & 12 & 27.72 & 2.517 & 0.16 & 0.9063 & \multirow[t]{5}{*}{2.513} \\
\hline & $\mathrm{ET}_{\mathrm{mo2}}$ & 24 & 27.57 & 2.514 & 0.04 & 0.8776 & \\
\hline & $\mathrm{ET}_{\mathrm{mo3}}$ & 36 & 27.75 & 2.516 & 0.12 & 0.8442 & \\
\hline & $\mathrm{ET}_{\mathrm{mo} 4}$ & 48 & 27.77 & 2.514 & 0.04 & 0.8058 & \\
\hline & $\mathrm{ET}_{\mathrm{mo5}}$ & 60 & 27.81 & 2.515 & 0.08 & 0.8479 & \\
\hline Mean & & & 27.72 & 2.515 & & & \\
\hline Stdev. & & & 0.09 & 0.001 & & & \\
\hline CV (\%) & & & 0.33 & 0.052 & & & \\
\hline
\end{tabular}

' $\mathrm{n}_{\text {modopt }}{ }^{\prime}=T_{\mathrm{mx}}$ power calibrated using the data points of column 3. $\mathrm{n}_{\text {modopt }}$ ' 11 -year $=T_{\mathrm{mx}}$ power calibrated using the eleven-year monthly averaged data points of each station 
to see whether there are clear differences among the data sets or not, it is necessary to evaluate the corresponding ET-TM $\mathrm{To}_{\text {mo }}$ values and to check how much they are close to the 1:1 slope line. Figure 1 depicts the trends and how close the plots are to the 1:1 slope line.

All the plots of the different number of data points of the five stations indicate almost overlap with the 1:1 slope line. Besides, all of the data points are completely within the $95 \%$ prediction bounds for all stations. There does not seem to be differences among the different number of data points. The statistical parameters, model tendencies and performance tests can show how close they are to each other, and the results are summarized in Table 4.

Table 4 shows the identical nature of the data sets in terms of statistical parameters. All of the $R^{2}$ values range from 0.8 to 0.92 , which indicate good fits. The slopes are also very close to one (with errors of less than 1\%). The fitted lines of all the five data sets of all the stations show overlap with the 1:1 slope lines. The CE of all the data sets is in the range of good or satisfactory. The tendencies by CRM either show very slight underestimation or perfect agreement, which by the way, also agrees with the model tendency of the 1:1 slope line. The RMSE values show errors not exceeding $0.278 \mathrm{~mm} \mathrm{day}^{-1}$ or (8.6\%). Since the mean values of the reference data are all greater than two, when the RMSE is divided by the mean values, our results are comparable and in some cases even less than what [7] obtained when they plotted calibrated Hargreaves method against FAO56-PM method. The errors by RMSE are slightly higher for stations that have relatively lower mean monthly averaged maximum temperatures and lower for those whose maximum temperatures are higher. Mean percent errors are almost uniform and are limited to $7 \%$ or less.

In general, the five data sets gave identical results with regard to all the tests and model performances, and hence, it is safe to conclude that taking monthly averaged data of 2 years or more is in no way superior to taking 1-year monthly averaged data points for calibration. Besides, the errors recorded by slope and by RMSE are relatively lower for the 1-year data points than the rest. Even if several studies indicate the benefit of calibration (e.g., $[5,7,21$, 22]), none of them indicated the number of data points necessary for calibration. In this study, however, as far as monthly averaged data points are concerned, it is sufficient to take 12-month data points in order to calibrate ' $n$.'

\subsection{Estimating the power of $T_{\mathrm{mx}}$ from daily data points}

Unlike the monthly averaged data points, only three data sets were considered for the daily data points. This is based on the assumption that if measurements are going to be performed for calibration purposes, the measurement should not exceed one month (30 days). For this purpose, the data points considered were those of 10,20 and 30 days. For each of these data sets, the $T_{m x}$ values were evaluated independently. The powers of $T_{\mathrm{mx}}\left(\mathrm{n}_{\text {modopt }}{ }^{\prime}\right)$ were also the values evaluated from the corresponding $T_{m x}$ and ET-PM values. The results are given in Table 5.

As observed from the table, the ' $n_{\text {modopt }}$ obtained for all the data points are close to the values obtained from evaluation of the eleven-year monthly averaged values (with percent error not exceeding 0.5 ). The percent error though slightly higher than what was obtained for the monthly averaged ones does not show differences among the three data sets. It also does not show any pattern. The standard deviations also revealed very low values and that tells that there are not much differences with the values obtained from different numbers of data points. However, the data points did not show good coefficient of determinations in all the cases.

Xu and Singh [28], Xystrakis and Matzarakis [30] in their study of thirteen empirical potential ET comparisons have also observed better patterns from the monthly averaged values than the daily values. In analysis of ET, location of meteorological stations is an important factor. Those that are close to water bodies are, for instance, subject to large variation in humidity related values depending on wind direction. The use of monthly averaged values smoothes out the variations [29,30], while the daily values are incapable of doing this. This seems to be the reason why the daily values did not perform as the monthly averaged ones.

The next step taken was to plot the ET values obtained (without intercept) by using the corresponding $T_{m x}$ and $n_{\text {optmod }}$ values given in Table 5 . The plots are shown in Fig. 2.

Even though the curve fits in all the cases were pretty close to the 1:1 slope lines, the fits were not that much satisfactory in all the cases. The $95 \%$ prediction bounds also showed few data points outside the bounds. The $R^{2}$ values were poor in this case as in the case of Table 5 . Averaging data has the ability to remove some irregularities and that seems to be the reason for the differences in $R^{2}$ between the monthly averaged data and the daily data points. Tendencies and performance tests for daily data are given in Table 6.

The performance tests by $C E$ and by ' $R$ ' and slope' did not do well in all the cases. However, performance tests by prediction bound, by CV and by MPE gave acceptable results. So also were the model tendencies by CRM, by slope and by 1:1 slope line. The RMSE is still limited to below $0.329 \mathrm{~mm} \mathrm{day}^{-1}$ or $9.1 \%$ relative error.

In general, the 30-day data points showed agreement by CRM, while the others showed slight underestimation. On the other hand, the $R^{2}$ values were slightly better for 


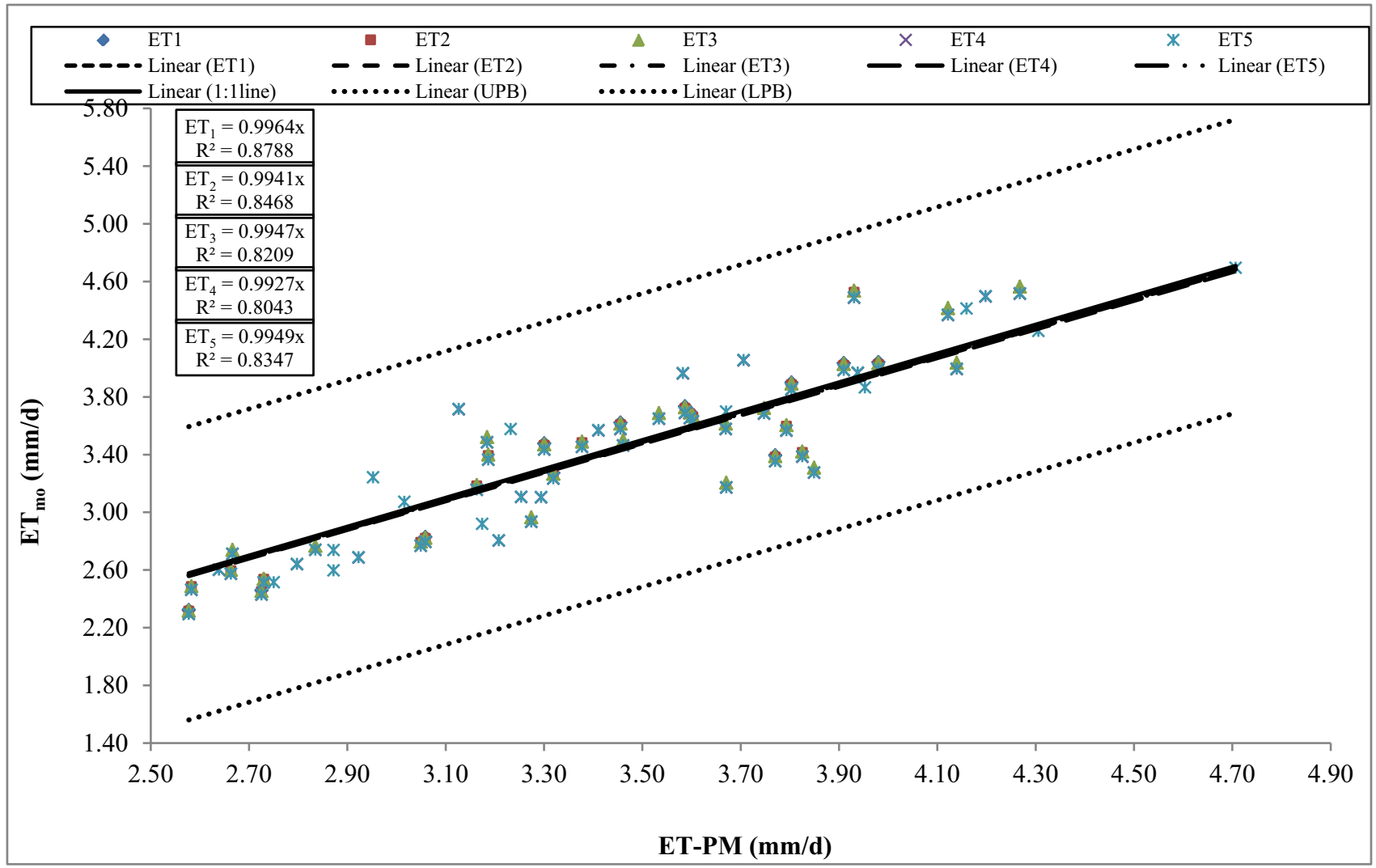

(Addis Ababa)



(Debre Birhan)

Fig. 1 Plots of $\mathrm{ET}_{\mathrm{mo}}$ versus ET-PM of the five stations shown separately

\section{SN Applied Sciences}




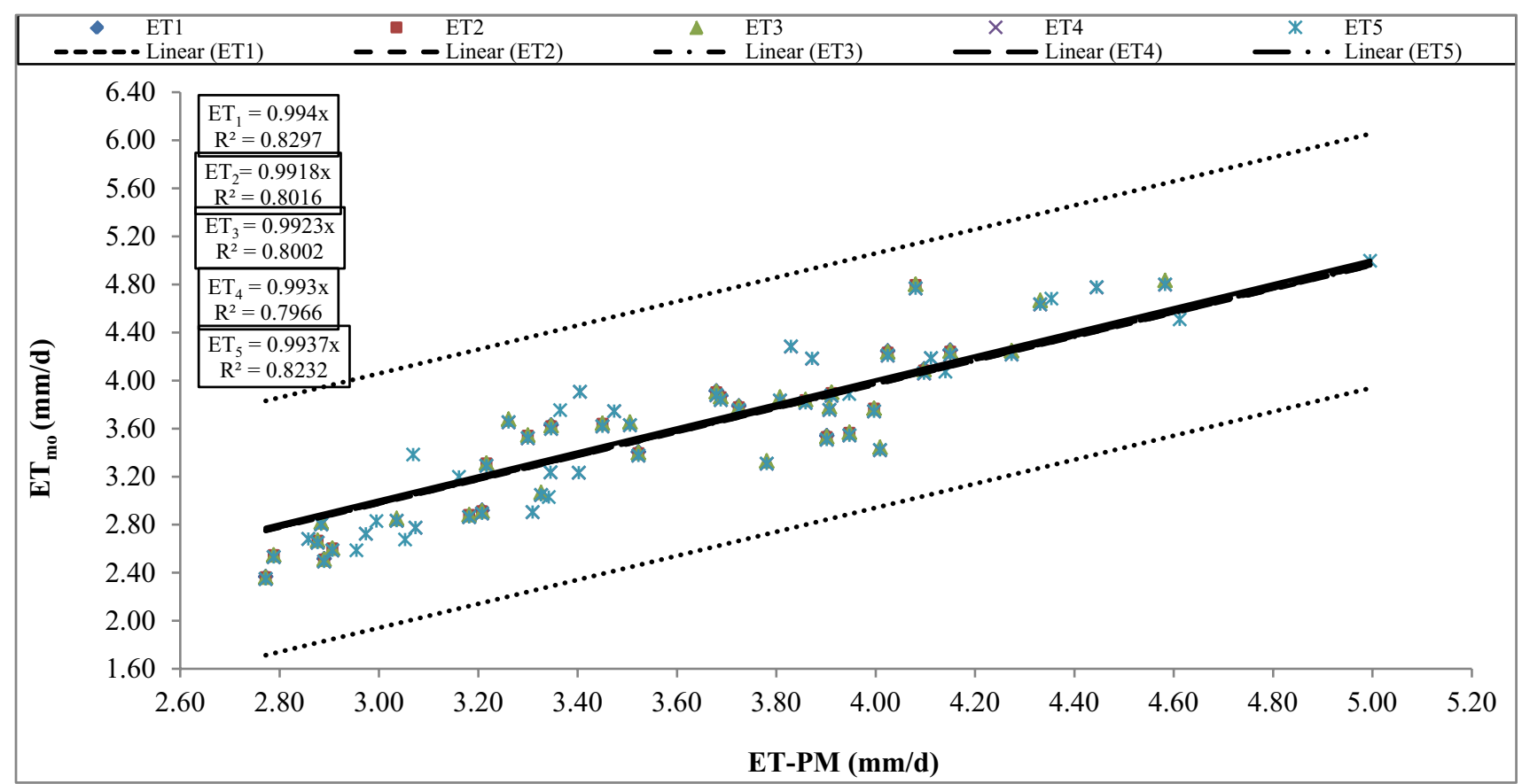

(Desse)



(Mekele)

Fig. 1 (continued)

the 20-day data points. Since the percent errors (Table 5) were nearly identical but slightly less for the 10-day data points, there does not seem to be differences among the three.
All in all, calibration of ' $n$ ' from the daily data points did not do as well as the monthly averaged data points. In spite of that, the optimized ' $n$ ' values are not that much different from the ones evaluated from the monthly averaged 


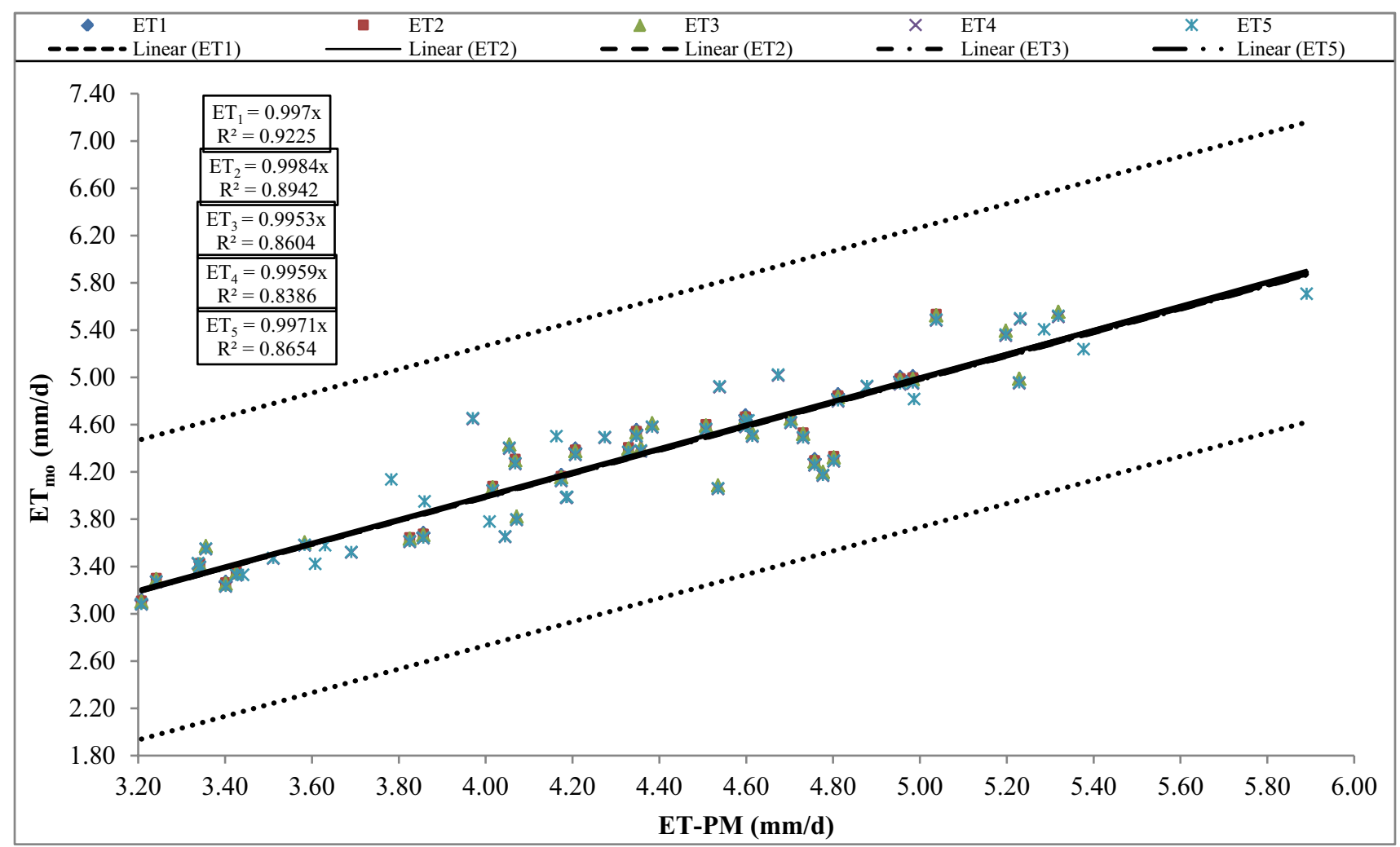

(Metehara)

Fig. 1 (continued)

values since the errors are less than $0.5 \%$. Therefore, if measurement is an option, 10-30-day measurement is sufficient to get the desired calibration of ' $n$.'

\subsection{Determination of $\boldsymbol{n}_{\text {clct }}$}

For meteorological stations that do not have complete data to use PM equation, it is imperative to estimate ' $n$ ' by some other method. Since latitude and altitude influence the maximum temperature of a given location, ' $n$ ' could be estimated from the two values. In this study, several trials were made to estimate the ' $n$ ' values from latitude, altitude and the overall averaged maximum temperature of the location $\left(T_{m x}\right)$. The value of ' $n$ ' obtained for each station was then expressed as ' $n_{\text {clct }}$ ' and the corresponding ETs were expressed as $\mathrm{ET}_{\text {nclct }}$. Equation 10 shows the final expression.

$\mathrm{ET}_{\mathrm{nclct}}=\frac{T_{\mathrm{mx}}^{n_{\mathrm{clct}}}}{48 \bar{T}_{\mathrm{mx}}-330}$
The modified TM method of ET estimation was done by using the average of the monthly averaged maximum temperatures of each station. Thereafter, calibration of ' $n$ ' was done by curve fitting the plot between ET-PM and the $T_{m x}$ using Eq. 10. The ' $n$ ' obtained from the curve fitting is ' $n_{\text {opt. }}$ ' In order to find the calculated value of ' $n$ ' $\left(n_{\text {clct }}\right)$, different combinations of latitude $(\varphi)$ altitude $(A)$ and with different powers of $T_{\mathrm{mx}}$ were tried by correlating the combination with the optimized ' $n$.'To find the correct ' $m$ ' value of Eq. 11, several curve fittings were made each time by varying ' $m$ ' value. Trials were made by considering ' $m$ ' values between 1 and 2.5 until the best fit that marks the optimized ' $\mathrm{m}$ ' was obtained. Curve fitting between

$x=\frac{(\varphi)(A)}{\overline{\bar{T}}_{\mathrm{mx}}^{m}}$

and $n_{\text {opt }}$ was made using MATLAB R2018a, and out of the tried functions, the two-term Fourier function gave the optimum result with $R^{2}=0.926, \mathrm{SSE}=0.00127$ and $\mathrm{RMSE}=0.0119$. Multiple trials were made by varying the 
Table 4 Statistical parameters and performance tests of ' $n$ ' optimization using monthly averaged data of five stations

\begin{tabular}{|c|c|c|c|c|c|c|c|c|}
\hline \multirow[t]{2}{*}{ Station } & \multirow[t]{2}{*}{ Method } & \multicolumn{3}{|c|}{ Statistical parameters } & \multirow[t]{2}{*}{ RMSE } & \multirow{2}{*}{\multicolumn{2}{|c|}{ CE }} & \multirow[t]{2}{*}{ CRM } \\
\hline & & $\overline{R^{2}}$ & & Slope $(b)$ & & & & \\
\hline \multirow[t]{5}{*}{ Addis Ababa } & $\mathrm{ET}_{\mathrm{mo} 1}$ & \multicolumn{2}{|l|}{0.8788} & 0.9964 & $0.19(5.6 \%)$ & \multicolumn{2}{|r|}{0.80} & 0.785 \\
\hline & \multicolumn{2}{|l|}{$\mathrm{ET}_{\mathrm{mo2}}$} & 0.8468 & 0.9941 & $0.22(6.4 \%)$ & \multicolumn{2}{|r|}{0.76} & 0.594 \\
\hline & \multicolumn{2}{|l|}{$\mathrm{ET}_{\mathrm{mo3}}$} & 0.8209 & 0.9947 & $0.24(7.0 \%)$ & \multicolumn{2}{|r|}{0.73} & 0.386 \\
\hline & $\mathrm{ET}_{\mathrm{mo4}}$ & 0.8043 & & 0.9927 & $0.26(7.6 \%)$ & & 0.69 & 0.194 \\
\hline & $\mathrm{ET}_{\mathrm{mo5}}$ & 0.8347 & & 0.9949 & $0.25(7.3 \%)$ & & 0.76 & 0.008 \\
\hline Debre Birhan & $\mathrm{ET}_{\mathrm{mo1}}$ & 0.9131 & & 0.9972 & $0.187(5.8 \%)$ & & 0.88 & 0.786 \\
\hline & $\mathrm{ET}_{\mathrm{mo2}}$ & 0.8918 & & 0.9939 & $0.213(6.6 \%)$ & & 0.85 & 0.599 \\
\hline & $\mathrm{ET}_{\mathrm{mo3}}$ & 0.8669 & & 0.9947 & $0.241(7.4 \%)$ & & 0.82 & 0.390 \\
\hline & $\mathrm{ET}_{\mathrm{mo} 4}$ & 0.8279 & & 0.9905 & $0.278(8.6 \%)$ & & 0.75 & 0.202 \\
\hline & $\mathrm{ET}_{\mathrm{mo5}}$ & 0.8668 & & 0.9939 & $0.258(7.9 \%)$ & & 0.81 & 0.010 \\
\hline Desse & $\mathrm{ET}_{\mathrm{mo1}}$ & 0.8297 & & 0.9940 & $0.253(7.0 \%)$ & & 0.661 & 0.786 \\
\hline & $\mathrm{ET}_{\mathrm{mo2}}$ & 0.8016 & & 0.9918 & $0.279(7.8 \%)$ & & 0.618 & 0.596 \\
\hline & $\mathrm{ET}_{\mathrm{mo3}}$ & 0.8002 & & 0.9923 & $0.283(7.9 \%)$ & & 0.654 & 0.390 \\
\hline & $\mathrm{ET}_{\mathrm{mo4}}$ & 0.7966 & & 0.9930 & $0.291(8.1 \%)$ & & 0.624 & 0.197 \\
\hline & $\mathrm{ET}_{\mathrm{mo5}}$ & 0.8232 & & 0.9937 & $0.284(7.9 \%)$ & & 0.708 & 0.010 \\
\hline Mekele & $\mathrm{ET}_{\mathrm{mo1}}$ & 0.9159. & & 0.9986 & $0.172(4.2 \%)$ & & 0.914 & 0.801 \\
\hline & $\mathrm{ET}_{\mathrm{mo2}}$ & 0.8905 & & 0.9959 & $0.200(4.9 \%)$ & & 0.889 & 0.611 \\
\hline & $\mathrm{ET}_{\mathrm{mo3}}$ & 0.8625 & & 0.9964 & $0.227(5.6 \%)$ & & 0.871 & 0.403 \\
\hline & $\mathrm{ET}_{\mathrm{mo} 4}$ & 0.8541 & & 0.9972 & $0.237(5.8 \%)$ & & 0.853 & 0.208 \\
\hline & $\mathrm{ET}_{\mathrm{mo5}}$ & 0.8232 & & 0.9961 & $0.235(5.8 \%)$ & & 0.880 & 0.001 \\
\hline Metehara & $\mathrm{ET}_{\mathrm{mo1}}$ & 0.9225 & & 0.9970 & $0.171(4.0 \%)$ & & 0.907 & 0.800 \\
\hline & $\mathrm{ET}_{\mathrm{mo2}}$ & 0.8942 & & 0.9984 & $0.203(4.7 \%)$ & & 0.877 & 0.607 \\
\hline & $\mathrm{ET}_{\mathrm{mo3}}$ & 0.8604 & & 0.9953 & $0.235(5.5 \%)$ & & 0.844 & 0.402 \\
\hline & $\mathrm{ET}_{\mathrm{mo4}}$ & 0.8386 & & 0.9959 & $0.256(5.9 \%)$ & & 0.806 & 0.207 \\
\hline & $\mathrm{ET}_{\mathrm{mo5}}$ & 0.8654 & & 0.9971 & $0.245(5.7 \%)$ & & 0.848 & 0.003 \\
\hline Station & Model tenden & & & Model & ormance & & & \\
\hline & By CRM & By slope & By $1: 1$ line & By CE & By $R^{2}$ and slope & PB & $\mathrm{CV}$ & MPE \\
\hline Addis Ababa & Slight UE & UE (0.36\%) & Overlap & G & G and G & All $w / n$ & 16.35 & 5.49 \\
\hline & Slight UE & UE (0.59\%) & Overlap & G & $\mathrm{G}$ and $\mathrm{G}$ & All $w / n$ & 16.98 & 5.48 \\
\hline & Slight UE & UE (0.53\%) & Overlap & $S$ & $\mathrm{G}$ and $\mathrm{G}$ & All $w / n$ & 16.86 & 5.86 \\
\hline & Slight UE & UE (0.73\%) & Overlap & $\mathrm{S}$ & $\mathrm{G}$ and $\mathrm{G}$ & All $w / n$ & 17.23 & 6.24 \\
\hline & Agreement & UE (0.51) \% & Overlap & G & $\mathrm{G}$ and $\mathrm{G}$ & All $w / n$ & 18.11 & 6.06 \\
\hline Debre Birhan & Slight UE & UE (0.28\%) & Overlap & G & $\mathrm{G}$ and $\mathrm{G}$ & All $w / n$ & 19.74 & 5.04 \\
\hline & Slight UE & UE (0.61\%) & Overlap & G & $\mathrm{G}$ and $\mathrm{G}$ & All $w / n$ & 20.64 & 4.82 \\
\hline & Slight UE & UE (0.53\%) & Overlap & G & $\mathrm{G}$ and $\mathrm{G}$ & All $w / n$ & 20.52 & 5.60 \\
\hline & Slight UE & UE (0.95\%) & Overlap & G & $\mathrm{G}$ and $\mathrm{G}$ & All $w / n$ & 20.98 & 6.79 \\
\hline & Slight UE & UE (0.61\%) & Overlap & G & G and $G$ & All $w / n$ & 22.07 & 6.21 \\
\hline Desse & Slight UE & UE (0.60\%) & Overlap & $\mathrm{S}$ & $\mathrm{G}$ and $\mathrm{G}$ & All $w / n$ & 17.21 & 6.96 \\
\hline & Slight UE & UE (0.80\%) & Overlap & $\mathrm{S}$ & $\mathrm{G}$ and $\mathrm{G}$ & All $w / n$ & 17.91 & 7.12 \\
\hline & Slight UE & UE (0.77\%) & Overlap & $\mathrm{S}$ & $\mathrm{G}$ and $\mathrm{G}$ & All $w / n$ & 17.78 & 6.97 \\
\hline & Slight UE & UE (0.70\%) & Overlap & $S$ & $\mathrm{G}$ and $\mathrm{G}$ & All $w / n$ & 18.18 & 7.36 \\
\hline & Slight UE & UE (0.63\%) & Overlap & $\mathrm{S}$ & $\mathrm{G}$ and $\mathrm{G}$ & All $w / n$ & 19.11 & 7.18 \\
\hline Mekele & Slight UE & UE (0.14\%) & Overlap & G & $\mathrm{G}$ and $\mathrm{G}$ & All $w / n$ & 15.34 & 2.92 \\
\hline & Slight UE & UE (0.41\%) & Overlap & G & $\mathrm{G}$ and $\mathrm{G}$ & All $w / n$ & 15.32 & 3.23 \\
\hline & Slight UE & UE (0.36\%) & Overlap & G & $\mathrm{G}$ and $\mathrm{G}$ & All $w / n$ & 15.30 & 4.00 \\
\hline & Slight UE & UE (0.28\%) & Overlap & G & G and $G$ & All $w / n$ & 15.58 & 4.29 \\
\hline & Agreement & UE (0.39\%) & Overlap & G & G and G & All $w / n$ & 16.21 & 4.27 \\
\hline
\end{tabular}


Table 4 (continued)

\begin{tabular}{|c|c|c|c|c|c|c|c|c|}
\hline \multirow[t]{2}{*}{ Station } & \multicolumn{3}{|c|}{ Model tendency } & \multicolumn{5}{|c|}{ Model performance } \\
\hline & By CRM & By slope & By $1: 1$ line & By CE & By $R^{2}$ and slope & PB & $\mathrm{CV}$ & $\overline{M P E}$ \\
\hline \multirow[t]{5}{*}{ Metehara } & Slight UE & UE (0.30\%) & Overlap & G & G and $G$ & All w/n & 14.85 & 3.00 \\
\hline & Slight UE & UE (0.16\%) & Overlap & G & G and $G$ & All w/n & 15.02 & 3.44 \\
\hline & Slight UE & UE (0.47\%) & Overlap & G & G and $G$ & All w/n & 14.79 & 4.14 \\
\hline & Slight UE & UE (0.41\%) & Overlap & G & $\mathrm{G}$ and $\mathrm{G}$ & All w/n & 15.06 & 4.55 \\
\hline & Agreement & UE (0.29\%) & Overlap & G & $\mathrm{G}$ and $\mathrm{G}$ & All w/n & 15.66 & 4.41 \\
\hline
\end{tabular}

Numbers in parenthesis next to RMSE values are relative errors in estimated ET

Table 5 Maximum

temperature power calibration using different numbers of daily data sets

\begin{tabular}{|c|c|c|c|c|c|c|c|}
\hline Station & ET code & Data points & $\begin{array}{l}\text { Average } \\
\bar{T}_{\mathrm{mx}}\left({ }^{\circ} \mathrm{C}\right)\end{array}$ & 'n ${ }_{\text {modopt }}$ ' & $\begin{array}{l}\text { Percent } \\
\text { difference }\end{array}$ & $R^{2}$ & ' $\mathrm{n}_{\text {modopt }}$ '11-year \\
\hline \multirow[t]{3}{*}{ Addis Ababa } & $\mathrm{ET}_{\mathrm{d} 1}$ & 10 & 24.34 & 2.486 & 0.38 & -1.2120 & 2.495 \\
\hline & $\mathrm{ET}_{\mathrm{d} 2}$ & 20 & 24.81 & 2.493 & 0.40 & -0.8578 & \\
\hline & $\mathrm{ET}_{\mathrm{d} 3}$ & 30 & 24.70 & 2.500 & 0.41 & -0.9298 & \\
\hline Mean & & & 24.62 & 2.493 & & & \\
\hline Stdev. & & & 0.25 & 0.007 & & & \\
\hline CV (\%) & & & 1.00 & 0.281 & & & \\
\hline \multirow[t]{3}{*}{ Debre Birhan } & $\mathrm{ET}_{\mathrm{d} 1}$ & 10 & 20.34 & 2.540 & 0.39 & -0.8156 & 2.540 \\
\hline & $E T_{d 2}$ & 20 & 20.81 & 2.556 & 0.42 & -0.0182 & \\
\hline & $\mathrm{ET}_{\mathrm{d} 3}$ & 30 & 20.70 & 2.563 & 0.44 & -0.3405 & \\
\hline Mean & & & 20.62 & 2.553 & & & \\
\hline Stdev. & & & 0.25 & 0.012 & & & \\
\hline CV (\%) & & & 1.19 & 0.462 & & & \\
\hline \multirow[t]{3}{*}{ Desse } & $E T_{d 1}$ & 10 & 23.34 & 2.506 & 0.36 & -1.178 & 2.524 \\
\hline & $\mathrm{ET}_{\mathrm{d} 2}$ & 20 & 23.81 & 2.515 & 0.38 & -0.5242 & \\
\hline & $\mathrm{ET}_{\mathrm{d} 3}$ & 30 & 23.70 & 2.522 & 0.39 & -0.7580 & \\
\hline Mean & & & 23.62 & 2.514 & & & \\
\hline Stdev. & & & 0.25 & 0.008 & & & \\
\hline CV (\%) & & & 1.04 & 0.319 & & & \\
\hline \multirow[t]{3}{*}{ Mekele } & $\mathrm{ET}_{\mathrm{d} 1}$ & 10 & 27.34 & 2.495 & 0.37 & -0.1611 & 2.511 \\
\hline & $\mathrm{ET}_{\mathrm{d} 2}$ & 20 & 27.81 & 2.511 & 0.40 & 0.3082 & \\
\hline & $\mathrm{ET}_{\mathrm{d} 3}$ & 30 & 27.70 & 2.518 & 0.41 & 0.0663 & \\
\hline Mean & & & 27.62 & 2.508 & & & \\
\hline Stdev. & & & 0.25 & 0.012 & & & \\
\hline CV (\%) & & & 0.89 & 0.470 & & & \\
\hline \multirow[t]{3}{*}{ Metehara } & $E T_{\mathrm{d} 1}$ & 10 & 28.34 & 2.510 & 0.39 & -0.2522 & 2.513 \\
\hline & $E T_{\mathrm{d} 2}$ & 20 & 28.81 & 2.518 & 0.41 & -0.0065 & \\
\hline & $\mathrm{ET}_{\mathrm{d} 3}$ & 30 & 28.70 & 2.523 & 0.42 & -0.2945 & \\
\hline Mean & & & 28.62 & 2.517 & & & \\
\hline Stdev. & & & 0.25 & 0.007 & & & \\
\hline CV (\%) & & & 0.86 & 0.261 & & & \\
\hline
\end{tabular}

' $\mathrm{n}_{\text {modopt }}$ ' $=T_{\mathrm{mx}}$ power calibrated using the data points of column $3 . \mathrm{n}_{\text {modopt }}$ ' 11-year $=T_{\mathrm{mx}}$ power calibrated using the eleven-year data points of each station, $\mathrm{ET}_{\mathrm{mo} 1}, \mathrm{ET}_{\mathrm{mo2}}$ and $\mathrm{ET}_{\mathrm{mo}}$, refer to the $\mathrm{ET}$ values evaluated 10, 20 and 30 data points of identical months and years, respectively 


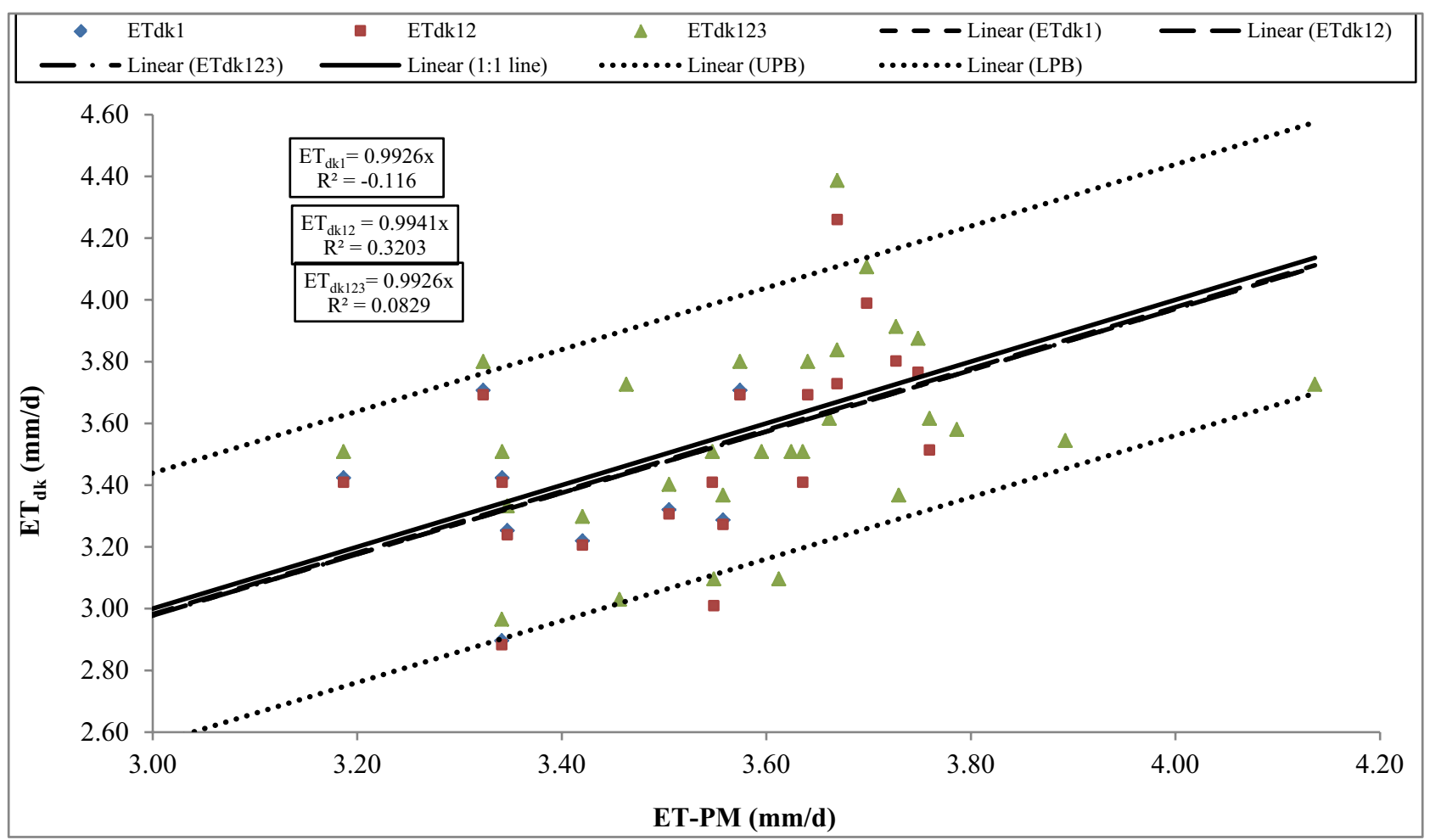

\section{(Addis Ababa)}

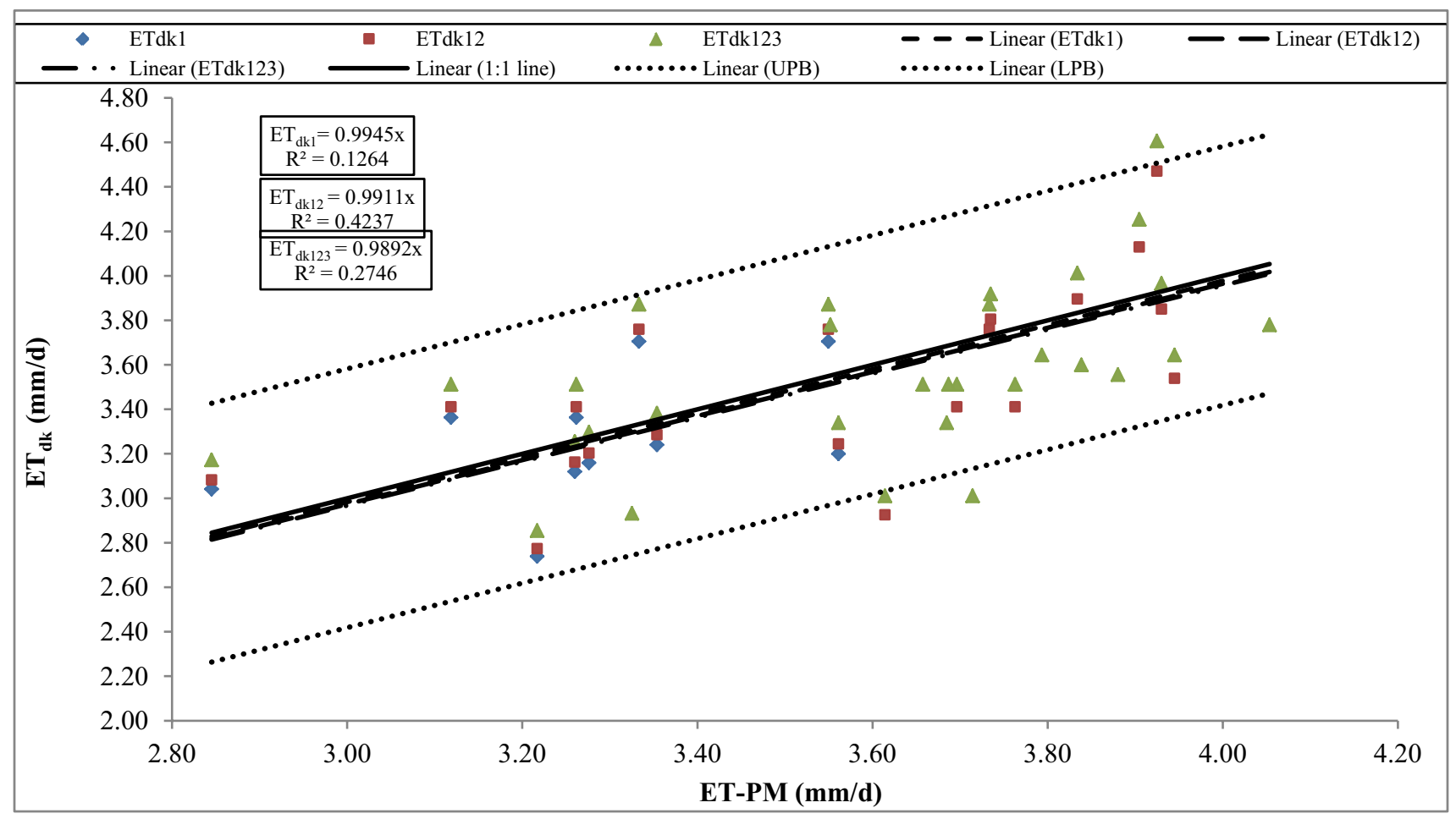

(Debre Birhan)

Fig. 2 Plots of $\mathrm{ET}_{\mathrm{dk}}$ versus ET-PM of the five stations shown separately 


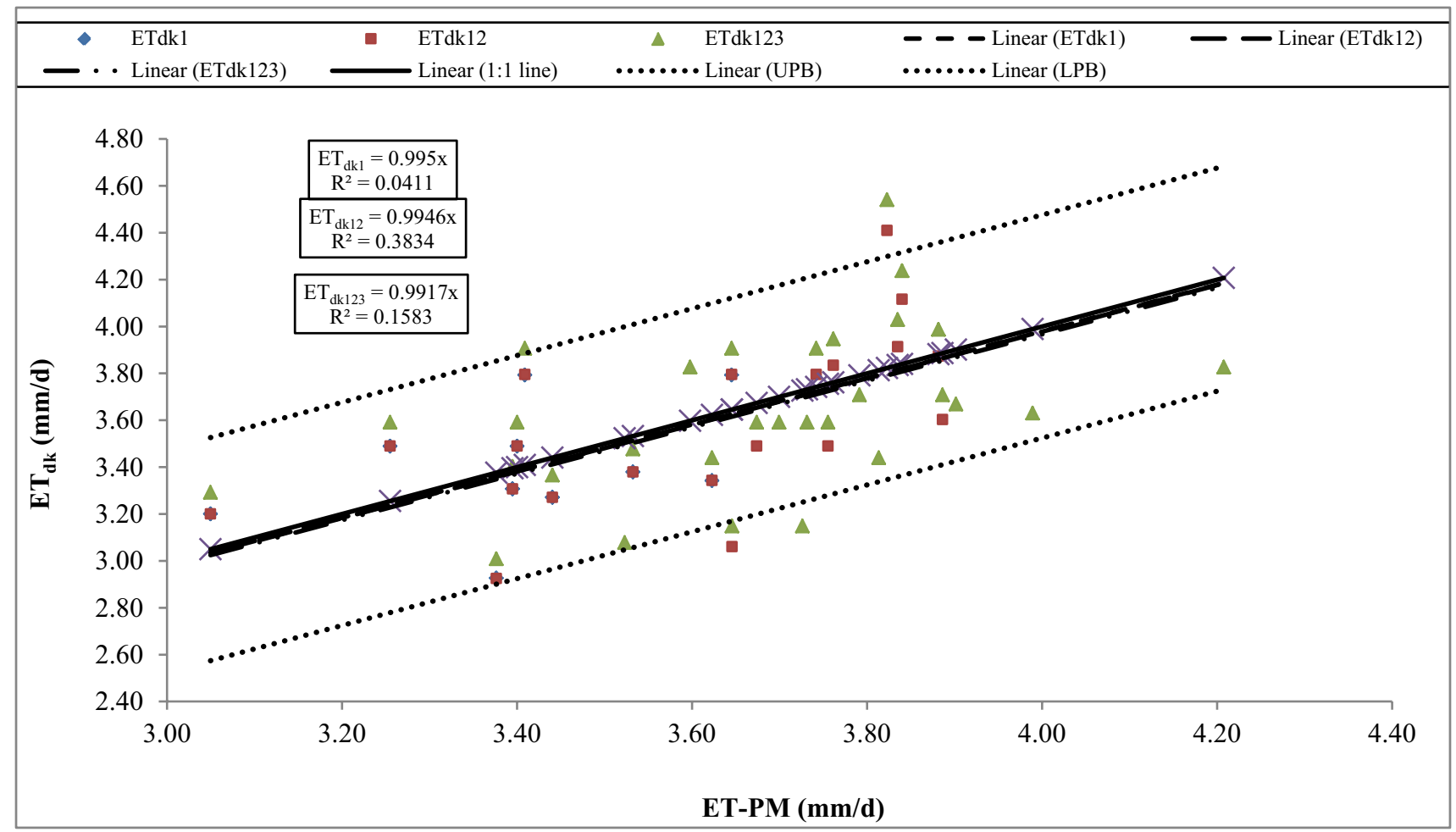

(Desse)

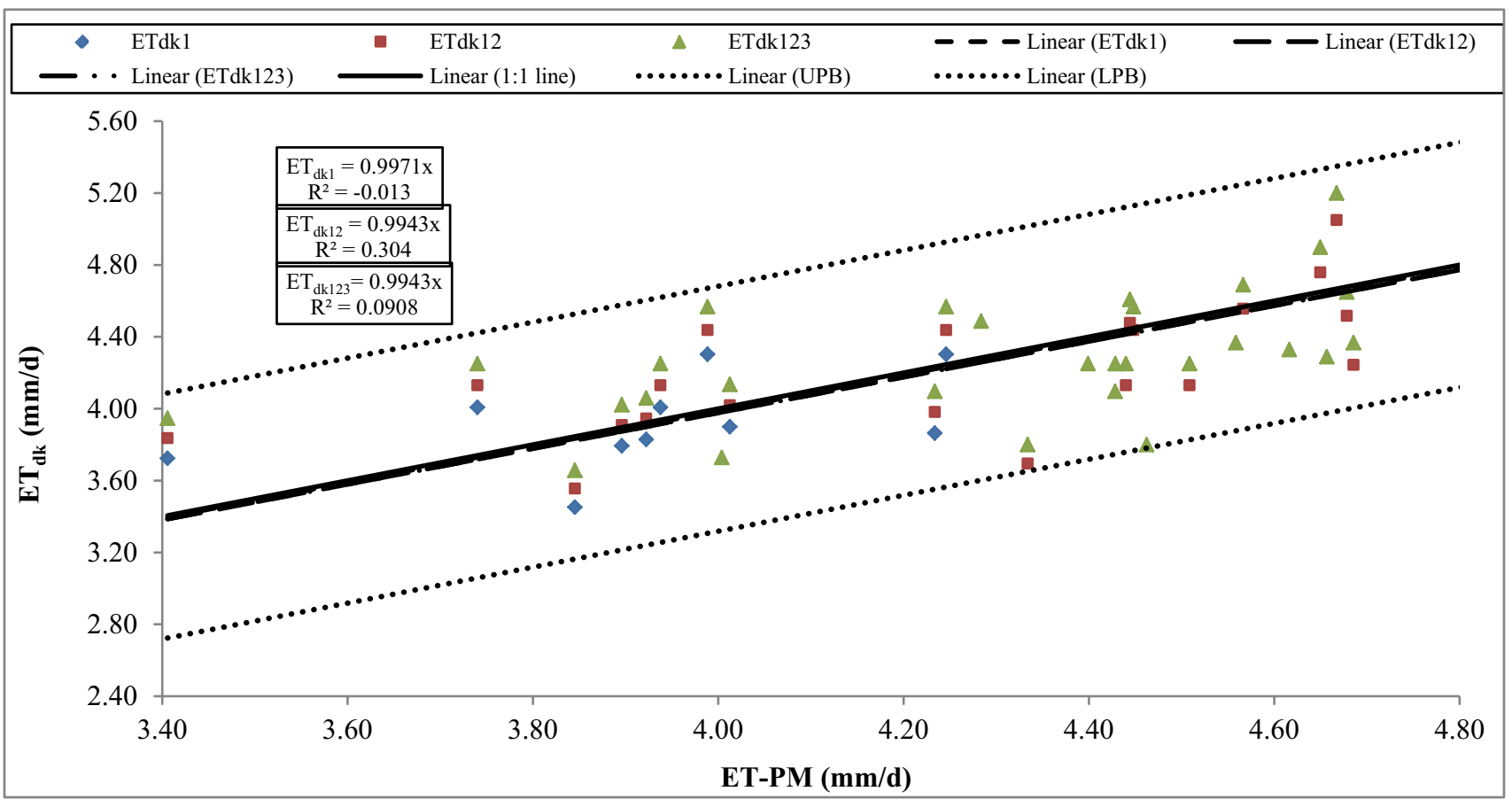

(Mekele)

Fig. 2 (continued) 


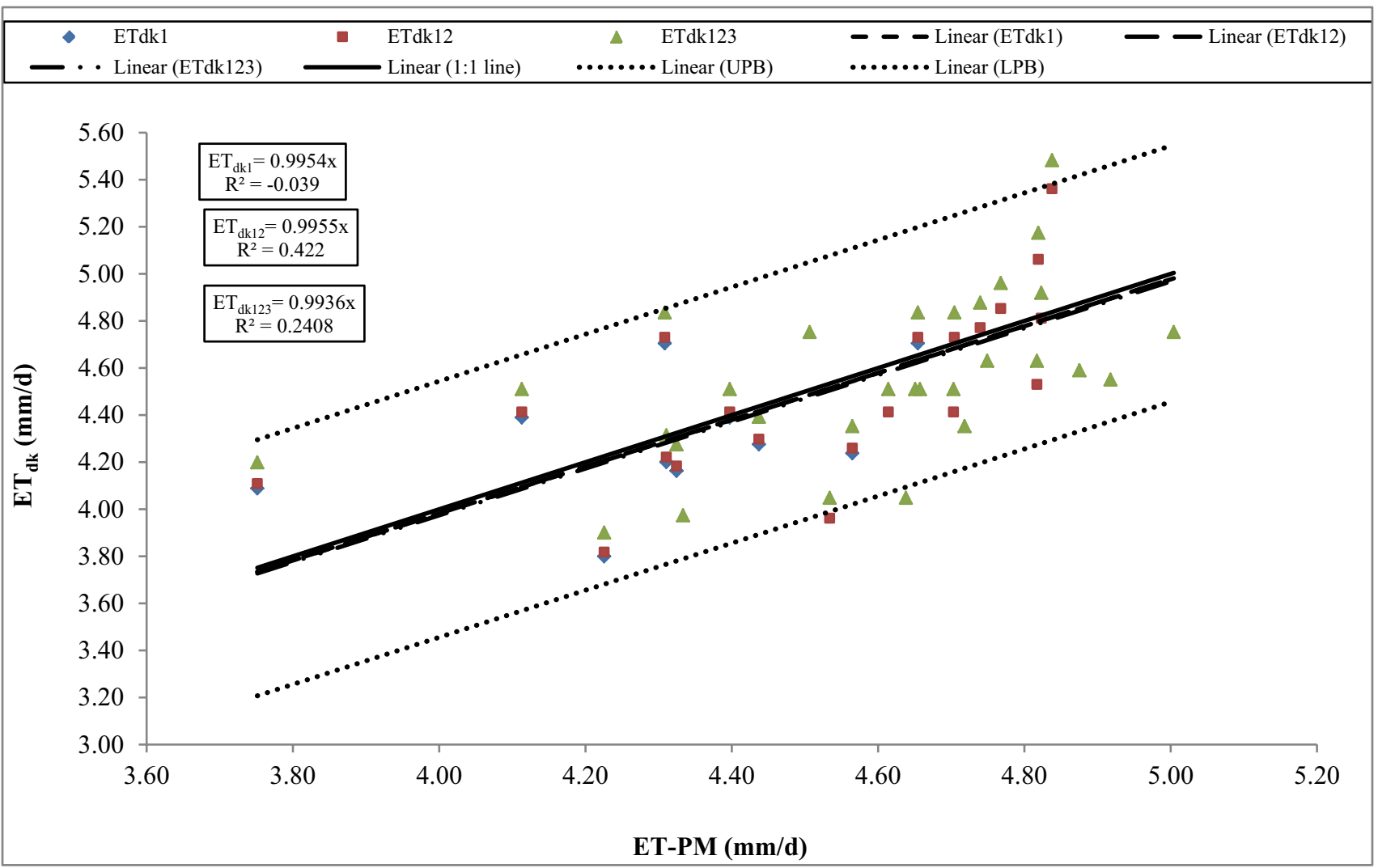

(Metehara)

Fig. 2 (continued)

power' $m$,' but after several attempts an ' $m$ ' value of 1.5 was found to be the best in terms of its $R^{2}$ value. The equation that relates $x$ and $n_{\text {clct }}$ has the form of

$$
\begin{aligned}
n_{\text {clct }}= & 2.522+0.009188 \cos (0.009428 x) \\
& -0.02731 \sin (0.009248 x) \\
& +0.007443 \cos (2 \times 0.009428 x) \\
& -0.01334 \sin (2 \times 0.009248 x)
\end{aligned}
$$

Table 7 shows summaries of the averaged $T_{m x}$ the optimized ' $n$ ' values $\left(n_{\text {opt }}\right.$ ) and the ' $n$ ' values calculated $\left(n_{\mathrm{clct}}\right)$ using Eq. 10 for all the eight stations.

As indicated in the table, in both cases the ' $n$ ' values are truncated at the third significant digit. This is important to suppress the large differences created by using ' $n$ ' value of one decimal place alone. The percent difference between the $n_{\text {opt }}$ and $n_{\text {clct }}$ is $1 \%$ or less. This is promising since the approach is a very farfetched.

\subsection{Plots of the three methods against ET-PM and curve fitting with intercepts}

The modified TM equation with $T_{\mathrm{mx}}$ power of 2.5 and the same equation with $T_{m x}$ power of ' $n_{\text {clct }}$ ' are the two methods that do not need calibration (data that satisfy PM equation). The performances of these two methods have to checked with respect to modified TM equation with $T_{\mathrm{mx}}$ power of ' $n_{\text {opt }}$ 'The plots of these three methods against the calculated PM equation are shown in Fig. 3.

As observed in all the curves, the fitted lines with intercepts generally showed relatively higher $R^{2}$ values. The fitted lines crossed the 1:1 slope line for two stations (Addet and Bahir Dar), and the intercepts are also greater than one for these stations. The problem with these two stations may be due data quality. For all the rest, the fitted lines are close to the 1:1 slope line and the intercepts are also less than 0.6 . The prediction bounds of most stations totally included all the data points. The data patterns of the former two stations are also slightly different from the rest. This might be due to some sort of error or instrument malfunction that must have resulted in measurement error in one of the parameters required to compute 
Table 6 Statistical parameters and performance tests of ' $n$ ' optimization using daily data of five stations

\begin{tabular}{|c|c|c|c|c|c|c|c|c|}
\hline \multirow[t]{2}{*}{ Station } & \multirow[t]{2}{*}{ Method } & \multicolumn{3}{|c|}{ Statistical parameters } & \multirow[t]{2}{*}{ RMSE } & \multirow[t]{2}{*}{ CE } & & \multirow[t]{2}{*}{ CRM } \\
\hline & & $R^{2}$ & & Slope $(b)$ & & & & \\
\hline \multirow[t]{3}{*}{ Addis Ababa } & $\mathrm{ET}_{\mathrm{d} 1}$ & \multicolumn{2}{|l|}{-0.1160} & 0.9926 & $0.247(6.9 \%)$ & \multicolumn{2}{|l|}{-1.18} & 0.688 \\
\hline & $\mathrm{ET}_{\mathrm{d} 2}$ & \multicolumn{2}{|l|}{0.3203} & 0.9941 & $0.272(7.6 \%)$ & \multicolumn{2}{|l|}{-0.86} & 0.349 \\
\hline & $E T_{d 3}$ & \multicolumn{2}{|l|}{0.0829} & 0.9926 & $0.300(8.4 \%)$ & \multicolumn{2}{|l|}{-0.93} & 0.006 \\
\hline \multirow[t]{3}{*}{ Debre Birhan } & $\mathrm{ET}_{\mathrm{d} 1}$ & \multicolumn{2}{|l|}{0.1264} & 0.9945 & $0.260(7.2 \%)$ & \multicolumn{2}{|l|}{-0.780} & 0.698 \\
\hline & $\mathrm{ET}_{\mathrm{d} 2}$ & \multicolumn{2}{|l|}{0.4234} & 0.9911 & $0.309(8.6 \%)$ & \multicolumn{2}{|l|}{0.00} & 0.349 \\
\hline & $\mathrm{ET}_{\mathrm{d} 3}$ & 0.2746 & & 0.9892 & $0.329(9.1 \%)$ & -0.32 & & 0.009 \\
\hline Desse & $E T_{d 1}$ & 0.0411 & & 0.9950 & $0.244(6.6 \%)$ & -1.19 & & 0.691 \\
\hline & $\mathrm{ET}_{\mathrm{d} 2}$ & 0.3834 & & 0.9946 & $0.279(7.6 \%)$ & -0.52 & & 0.349 \\
\hline & $E T_{d 3}$ & 0.1583 & & 0.9917 & $0.310(8.4 \%)$ & -0.76 & & 0.007 \\
\hline Mekele & $E T_{d 1}$ & 0.0130 & & 0.9971 & $0.246(5.7 \%)$ & -0.16 & & 0.697 \\
\hline & $\mathrm{ET}_{\mathrm{d} 2}$ & 0.3040 & & 0.9943 & $0.299(6.9 \%)$ & 0.31 & & 0.347 \\
\hline & $\mathrm{ET}_{\mathrm{d} 3}$ & 0.0908 & & 0.9943 & $0.324(7.5 \%)$ & 0.06 & & 0.003 \\
\hline Metehara & $\mathrm{ET}_{\mathrm{d} 1}$ & -0.039 & & 0.9954 & $0.265(5.8 \%)$ & -0.24 & & 0.688 \\
\hline & $E T_{d 2}$ & 0.422 & & 0.9955 & $0.282(6.2 \%)$ & -0.01 & & 0.345 \\
\hline & $\mathrm{ET}_{\mathrm{d} 3}$ & 0.241 & & 0.9936 & $0.305(6.7 \%)$ & -0.30 & & 0.005 \\
\hline Station & Model tender & & & Model & ormance & & & \\
\hline & By CRM & By slope & By $1: 1$ line & By CE & By $R^{2}$ and slope & PB & $\mathrm{CV}$ & MPE \\
\hline Addis Ababa & Slight UE & UE (0.74\%) & Slight UE & $\mathrm{P}$ & $P$ and $G$ & All in & 7.34 & 6.64 \\
\hline & Slight UE & UE (0.59\%) & Slight UE & $\mathrm{P}$ & $P$ and $G$ & Most in & 9.68 & 6.47 \\
\hline & Agreement & UE (0.74\%) & Slight UE & $P$ & $P$ and $G$ & Most in & 8.94 & 2.13 \\
\hline Debre Birhan & Slight UE & UE (0.55\%) & Slight UE & $P$ & $P$ and $G$ & All in & 8.96 & 7.14 \\
\hline & Slight UE & UE (0.89\%) & Slight UE & $P$ & $P$ and $G$ & Most in & 11.83 & 7.41 \\
\hline & Agreement & UE (1.10\%) & Slight UE & $P$ & $P$ and $G$ & Most in & 10.95 & 7.95 \\
\hline Desse & Slight UE & UE (0.50\%) & Overlap & $P$ & $P$ and $G$ & All in & 7.71 & 6.41 \\
\hline & Slight UE & UE (0.54\%) & Overlap & $\mathrm{P}$ & $\mathrm{P}$ and $\mathrm{G}$ & Most in & 10.17 & 6.48 \\
\hline & Agreement & UE (0.83\%) & Overlap & $\mathrm{P}$ & $P$ and $G$ & Most in & 9.41 & 7.23 \\
\hline Mekele & Slight UE & UE (0.29\%) & Overlap & $\mathrm{P}$ & $P$ and $G$ & All in & 6.56 & 5.46 \\
\hline & Slight UE & UE (0.57\%) & Overlap & $\mathrm{P}$ & $P$ and $G$ & Most in & 8.69 & 5.72 \\
\hline & Agreement & UE (0.57\%) & Overlap & $\mathrm{P}$ & $P$ and $G$ & Most in & 8.03 & 6.64 \\
\hline Metehara & Slight UE & UE (0.46\%) & Slight UE & $\mathrm{P}$ & $P$ and $G$ & All in & 6.36 & 5.34 \\
\hline & Slight UE & UE (0.45\%) & Slight UE & $\mathrm{P}$ & $P$ and $G$ & Most in & 8.41 & 5.13 \\
\hline & Agreement & UE (0.64\%) & Slight UE & $\mathrm{P}$ & $P$ and $G$ & Most in & 7.77 & 5.68 \\
\hline
\end{tabular}

Numbers in parenthesis next to RMSE values are relative errors in estimated ET

ET-PM equation. Semu [23] has also mentioned about data quality issues in stations found in rural areas of Africa. The proximity of the meteorological station close to the water body may also have its own influence [30]. The use of curve fitting with intercept is advantageous in order to see how the slope varies when the fits are done without intercepts. Summaries of statistical parameters, model tendencies and performance tests of the three methods are shown in Table 8.

Estimation of ET using calculated ' $n$ ' yielded CE of either good or satisfactory for six stations and poor for Addet and Dangla. Model tendency by CRM showed slight overestimation or underestimation for all the stations. So also is the 1:1 slope line except in the case of Addet and Bahir Dar. Performances by $R^{2}$ and slope were all good except in the case of Addet. The highest RMSE for the ET-TM $\mathrm{Tmd}_{\text {mod }}$ is $0.66 \mathrm{~mm}$ day $^{-1}$ or $17.3 \%$ error, while for $\mathrm{ET}_{\text {nclct }}$ is $0.585 \mathrm{~mm} \mathrm{day}^{-1}$ or $15.9 \%$. The highest for the modified and ' $n$ ' calibrated ET (ET-TM modopt ) is $0.498 \mathrm{~mm}^{\text {day }}{ }^{-1}$ or $13.5 \%$. The highest values in all the cases were observed for Dangla station. Except in one case (Mekele station), in all the other cases $\mathrm{ET}_{\text {nclt }}$ outperformed ET-TM $\mathrm{M}_{\text {mod }}$ and gave results close to the ET-TM modopt $_{\text {. }}$

In terms of model tendency by slope, $\mathrm{ET}_{\text {nclc }}$ outper-

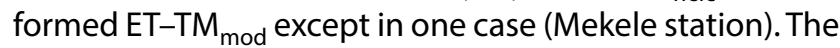

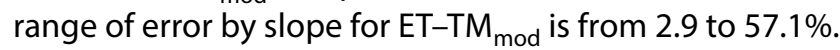


Table 7 Summary table of $T_{m x^{\prime} \text { opt }}$ and $\mathrm{n}_{\mathrm{clct}}$

\begin{tabular}{llllll}
\hline Station & $T_{\mathrm{mx}}$ & $n_{\mathrm{opt}}$ & $(\varphi)(\mathrm{A}) /\left(T_{\mathrm{mx}}\right)^{1.5}$ & $n_{\mathrm{clc}}$ & $\%$ difference \\
\hline Addis Ababa & 23.74 & 2.494 & 177.416 & 2.489 & 0.20 \\
Addet & 25.57 & 2.475 & 189.926 & 2.492 & -0.68 \\
Bahir Dar & 26.82 & 2.482 & 147.219 & 2.485 & -0.12 \\
Dangla & 25.72 & 2.490 & 182.500 & 2.464 & 1.06 \\
Debre Birhan & 19.86 & 2.540 & 291.452 & 2.518 & 0.87 \\
Desse & 22.86 & 2.524 & 258.574 & 2.512 & 0.48 \\
Mekele & 26.86 & 2.511 & 191.227 & 2.493 & 0.72 \\
Metehara & 27.86 & 2.513 & 54.630 & 2.509 & 0.16 \\
\hline
\end{tabular}

$A=$ altitude $(\mathrm{m}), \varphi=$ latitude $\left({ }^{\circ}\right), \mathrm{T}_{\mathrm{mx}}=$ averaged maximum temperature $\left({ }^{\circ} \mathrm{C}\right), n_{\mathrm{opt}}=$ the optimized $\mathrm{n}$ value given at the last column of Table 3, the $n_{\text {clct }}$ is the ' $n$ ' calculated by the function obtained after curve fitting (Eq. 12), and \% error is the percent difference of $n_{\text {clct }}$ with respect to $n_{\mathrm{opt}}$

For $\mathrm{ET}_{\text {nclc }}$ it is from 1.6 to $52.6 \%$. For the modified method with ' $n$ ' calibrated, the range is from 2.7 to $43.4 \%$. All in all, while calibration of ' $n$ ' is still the best option, it is better to calculate ' $n$ ' from altitude, latitude and $T_{m x}$ whenever calibration is not an option. Comparison between modified with $n=2.5$ (ET-TM mod ), the modified with $n$ calibrated (ET-TM $\left.\mathrm{T}_{\text {modopt }}\right)$ and modified with $n=\mathrm{n}_{\text {clclt }}\left(\mathrm{ET}_{\text {nclct }}\right)$ is summarized in Table 9.

The ET with the calculated ' $n$ 'value $\left(n_{\text {clct }}\right)$ has performed better than the modified (ET-TM mod ) in terms of percent difference by slope, CE and MPE. All the three methods were identical in terms of performance test by ' $R^{2}$ and slope.' In general, the modified equation with ' $n$ ' calculated $\left(\mathrm{ET}_{\text {nclct }}\right)$ is a good option whenever data satisfying PM equation is not available for calibration. However, this method has to be tested on data of independent stations in order to validate the applicability of the method.

Temperature extreme and radiation are the two dominant drivers of evapotranspiration $[8,21]$, which means, to get a reasonable estimate of $\mathrm{ET}$, equations that incorporate the two parameters tend to outperform the methods that incorporate temperature alone. On the other hand, Wang et al. [27] emphasize the role of wind speed as well. But in reality, all existing most temperature-based methods directly or indirectly incorporate radiation, at least in the form of sunshine hours [21]. Even these methods do not perform equally well [15] at all locations without calibrations $[5,7,16]$. For instance, Medeiros et al. [18] propose the method of correction based on error autocorrelation and linear regression for local estimates improvement for temperature-based ET estimation methods. Edebeatu [10] strongly recommends the empirical ET models be either modified or the coefficients be calibrated for better estimation of ET that agrees with the FAO56-Pm method. But, when temperature data alone are what is available, the use of methods that incorporate sunshine hours is not an option. Since temperature extreme that has influence on ET is the maximum daily temperature, the choice of Temesgen and Melesse in using solely $T_{m x}$ in their equation seems appropriate. What is observed in this case is that their purely temperature-based equation works well with modifications and when calibrated.

\subsection{Testing applicability of $\boldsymbol{n}_{\text {clct }}$ with data of other stations}

Two stations (Hawassa and Zeway) were selected to test the accuracy of $n_{\text {clct }}$ or for validation. This is necessary to see the applicability of Eq. 10 for other locations whose data have not been included during the determination of $n_{\text {clct }}$ (Eq. 12). The two stations have latitude, altitude and average maximum temperatures given in Table 10.

For calculation of $n_{\text {clct }}$ from column 5, Eq. 12 was used. The calculated ' $n$ ' in both cases are close to each other since the two areas have altitudes and maximum temperatures close to each other. They are also not that much far apart in terms of latitude. The plots and the linear curve fit between $\mathrm{ET}_{\text {est }}$ and ET-PM, with and without intercepts, are shown in Fig. 4. $\mathrm{ET}_{\text {est }}$ of the vertical axis in the figures is representing ET-TM $\mathrm{Emd}_{\text {mod }}, \mathrm{ET}-\mathrm{TM}_{\bmod 2}$ $\mathrm{ET}_{\text {nclct1 }}$ and $\mathrm{ET}_{\text {nclct2}}$.

Hawassa data used for the test are daily ET values of 1 month, whereas the Zeway data are monthly averaged values that span 11 years. In the case of Hawassa, the data points did not give satisfactory results as the monthly averaged values of Zeway. The summarized results of the two methods are given in Table 11.

The performance of ET-TM $M_{\text {mod }}$ and $\mathrm{ET}_{\text {nclct }}$ is almost identical in the case of Hawassa station. The ET-TM mod has error of $13.6 \%$ (from plot without intercept), while that of the $\mathrm{ET}_{\text {nclct }}$ is $11.4 \%$ (slightly better). Their $R^{2}$ values are also identical, but both methods overestimated ET.

In the case of Zeway, both methods gave identical results. All the four fit-lines almost overlap, but they all underestimated the ET. The percent differences by slope (of fit without intercept) are $9.85 \%$ and $10.5 \%$ for $\mathrm{ET}-\mathrm{TM}_{\text {mod }}$ and $\mathrm{ET}_{\text {nclct }}$ methods, respectively. Their $R^{2}$ values are also identical, which means both methods performed fairly well for Zeway station.

Looking at both methods, their performances improve when the monthly averaged maximum temperature data are considered instead of the daily data. That is why the two methods performed fairly well for Zeway for which 


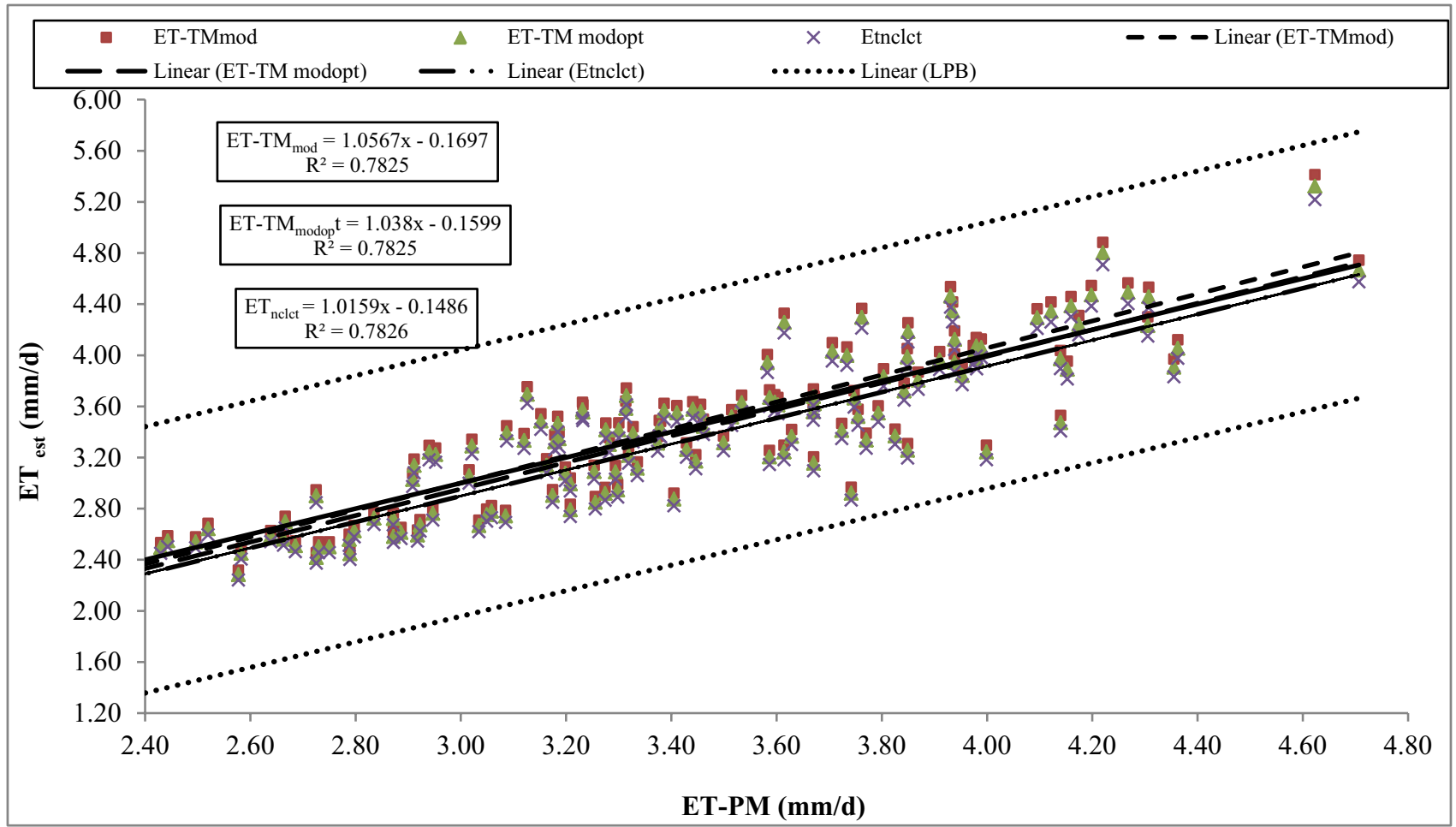

(Addis Ababa)

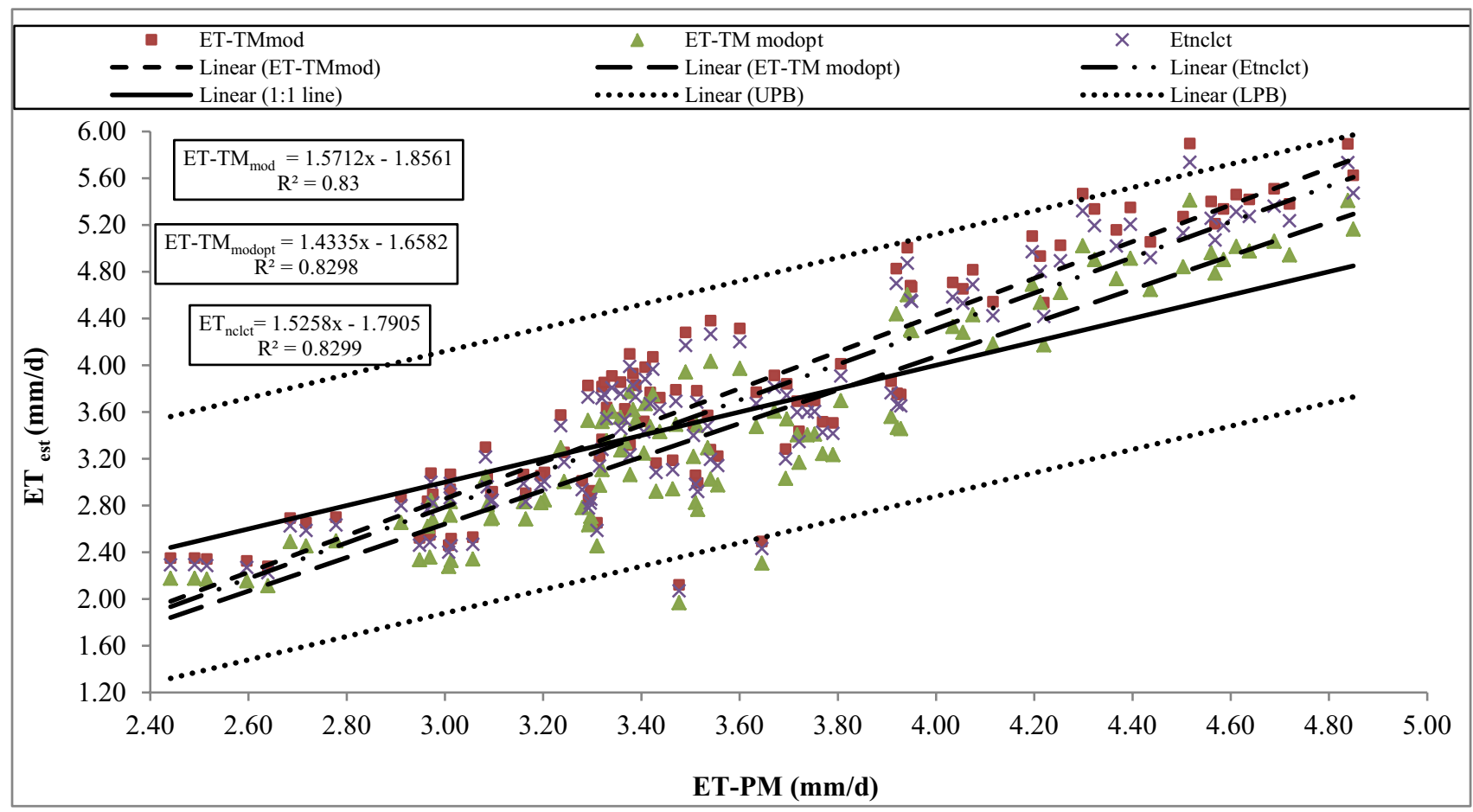

(Addet)

Fig. 3 Plots and linear curve fits with intercepts of the three methods against the calculated PM data shown for the eight stations separately 


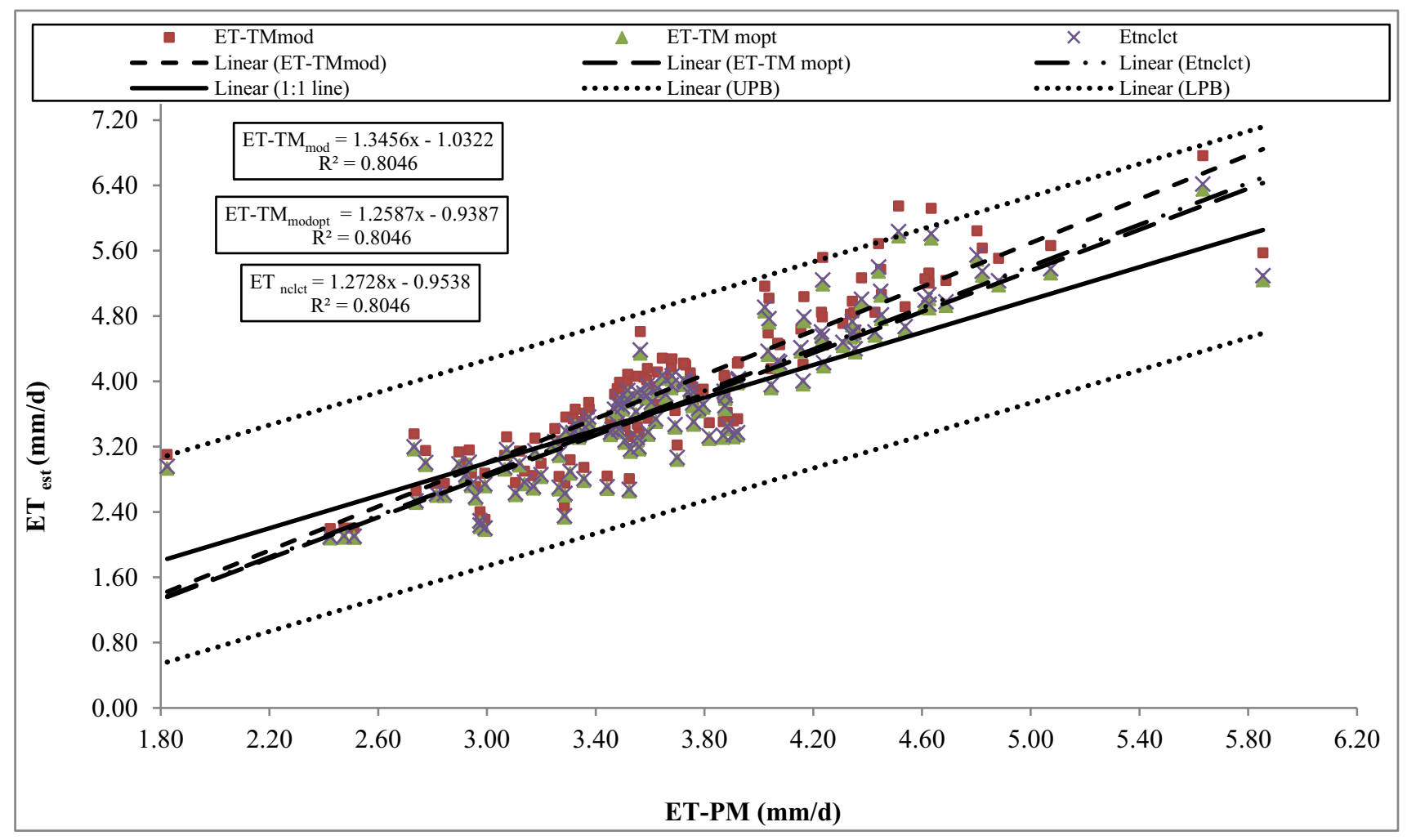

(Bahir Dar)

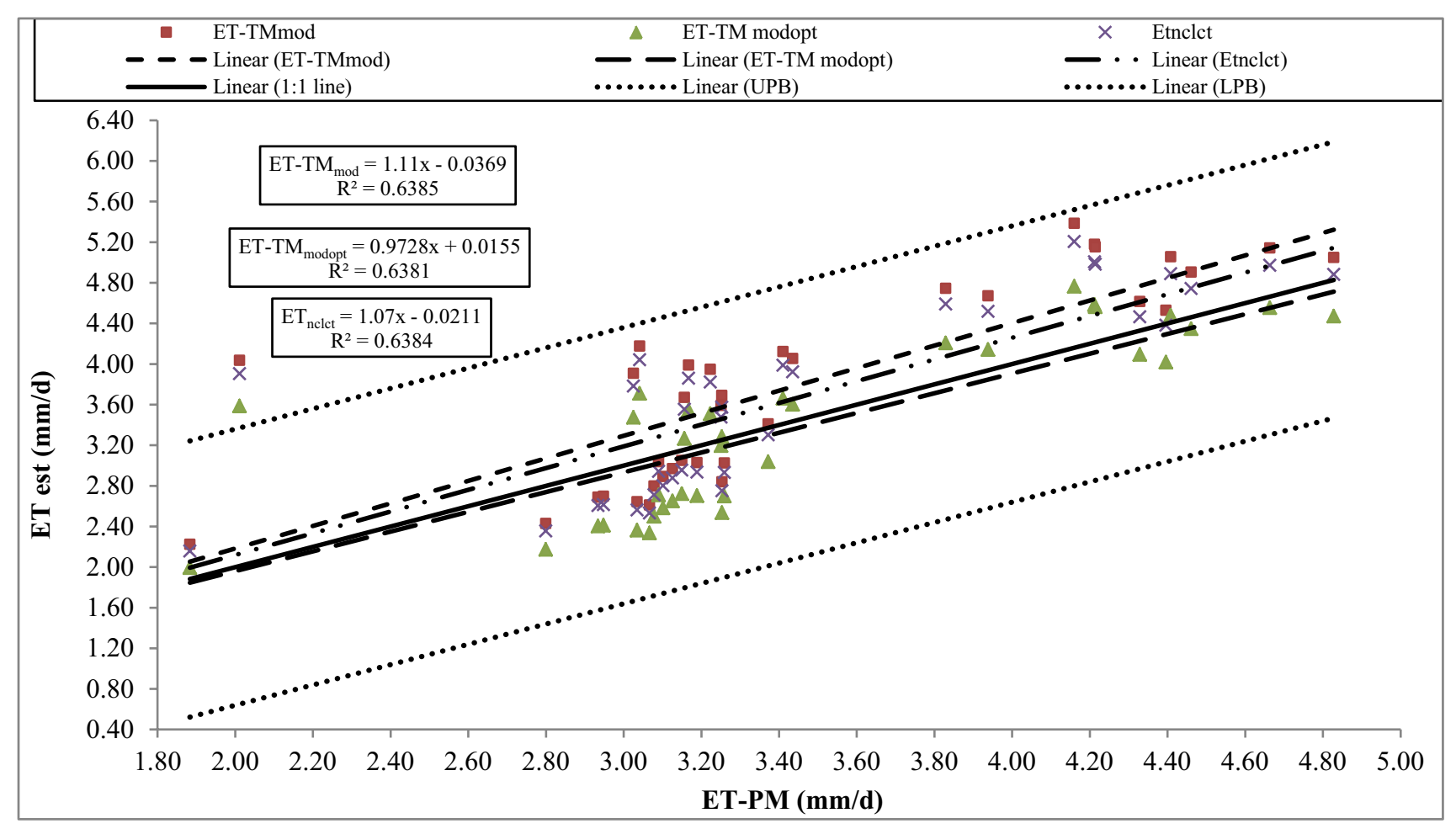

(Dangla)

Fig. 3 (continued) 


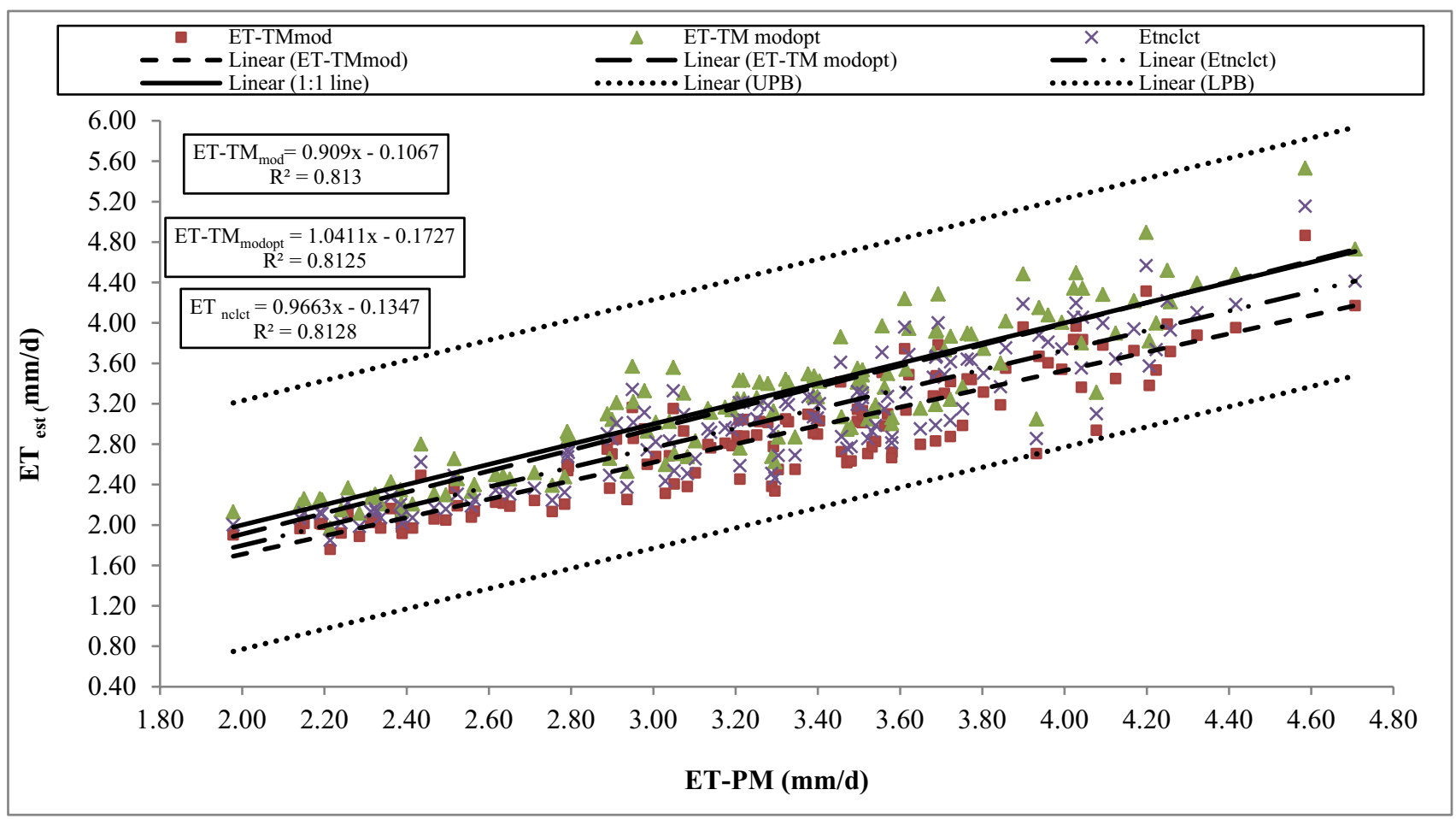

(Debre Birhan)

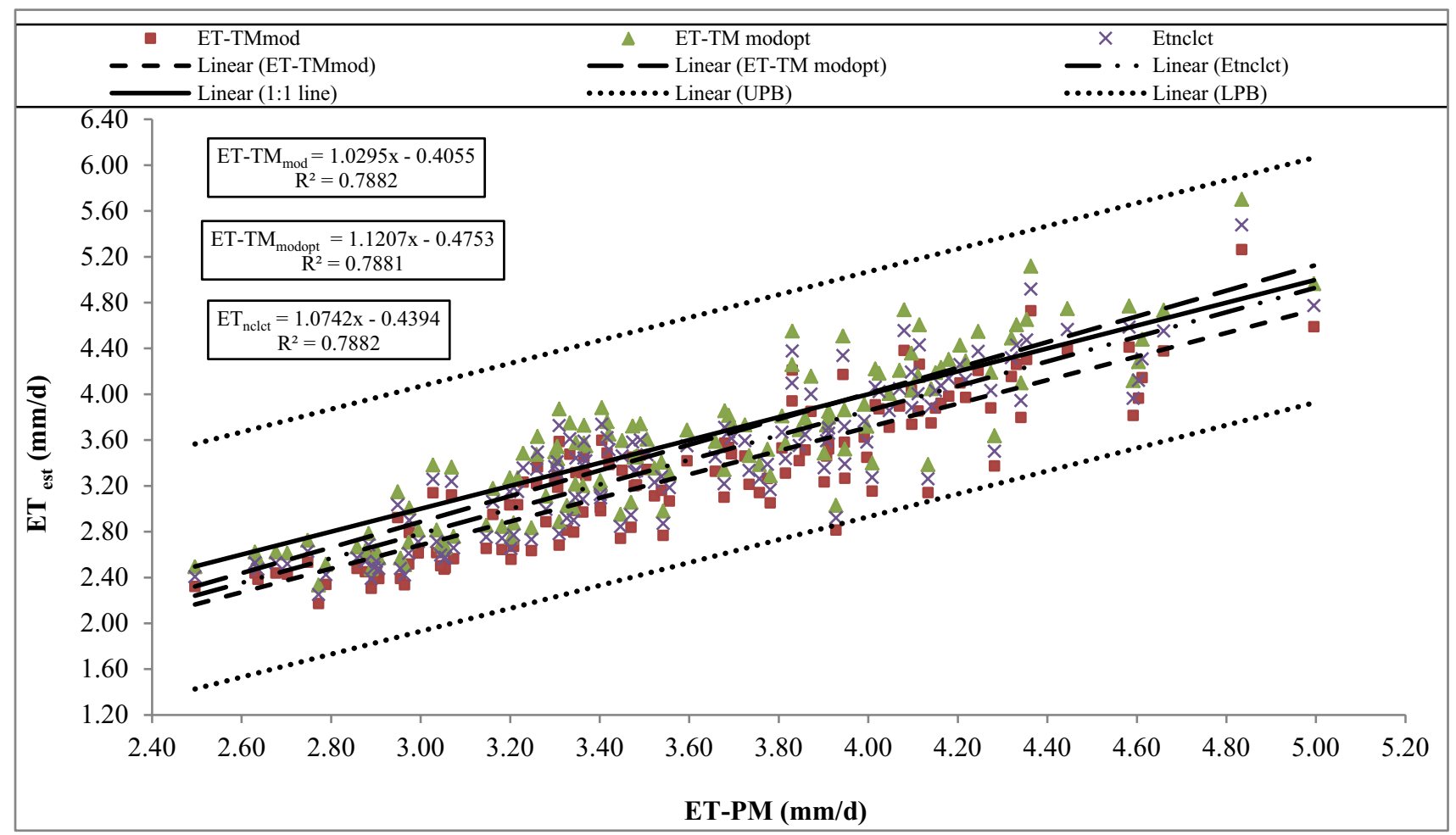

(Desse)

Fig. 3 (continued) 




\section{(Mekele)}

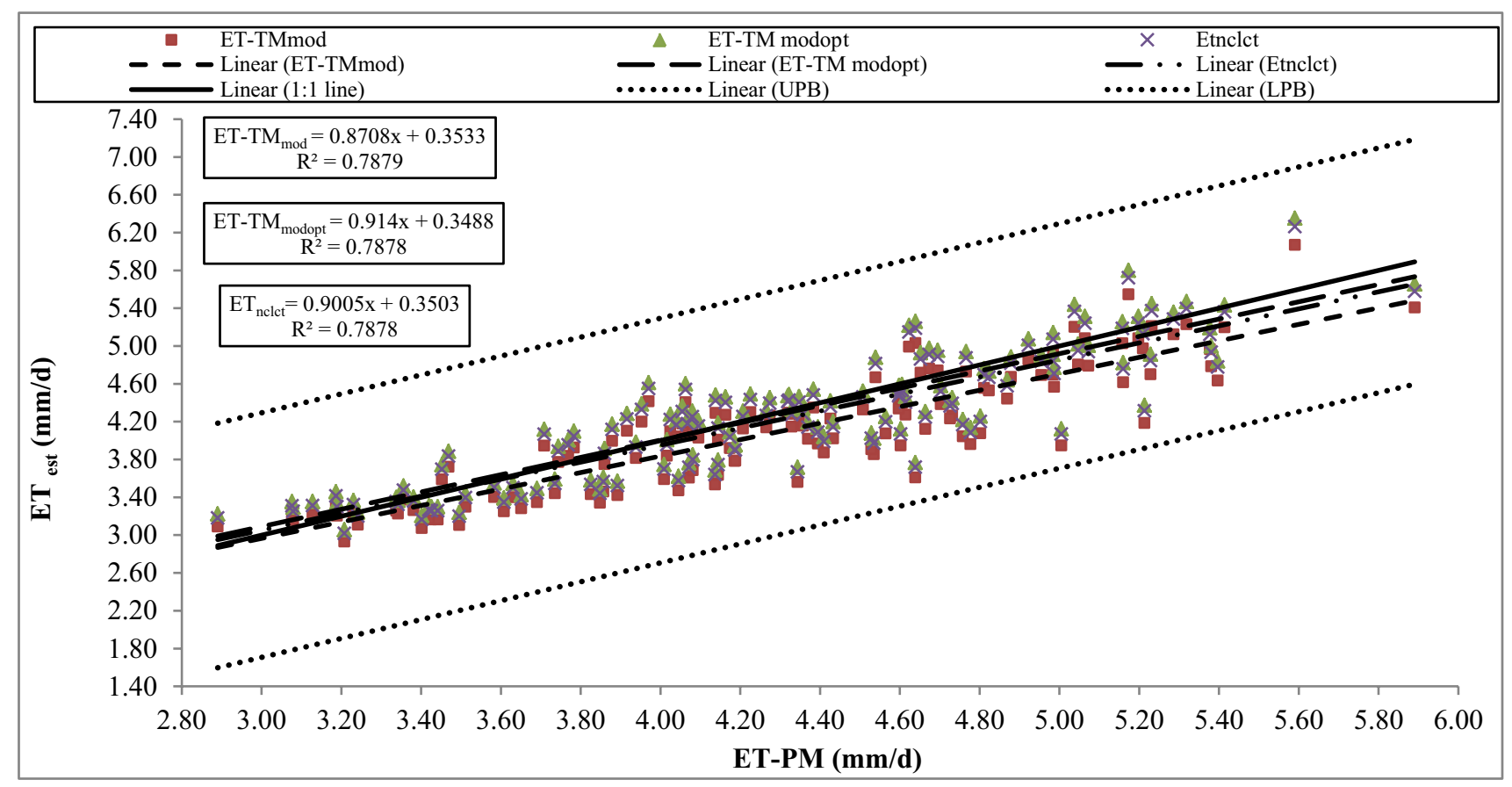

(Metehara)

Fig. 3 (continued) 
Table 8 Statistical parameters and performance tests of the three methods

\begin{tabular}{|c|c|c|c|c|c|c|c|c|}
\hline \multirow[t]{2}{*}{ Station } & \multirow[t]{2}{*}{ Method } & \multicolumn{3}{|c|}{ Statistical parameters } & \multirow{2}{*}{\multicolumn{2}{|c|}{ RMSE }} & \multirow[t]{2}{*}{ CE } & \multirow[t]{2}{*}{ CRM } \\
\hline & & $R^{2}$ & Slope $(b)$ & Int. (a) & & & & \\
\hline \multirow[t]{3}{*}{ Addis Ababa } & ET-TM mod & 0.783 & 1.057 & -0.170 & \multicolumn{2}{|c|}{$0.292(8.5 \%)$} & 0.68 & -0.007 \\
\hline & ET-TM modopt $_{1}$ & 0.783 & 1.038 & -0.160 & \multicolumn{2}{|c|}{$0.286(8.4 \%)$} & 0.70 & 0.009 \\
\hline & $\mathrm{ET}_{\text {nclct }}$ & 0.783 & 1.016 & -0.1 .49 & \multicolumn{2}{|c|}{$0.294(8.6 \%)$} & 0.68 & 0.028 \\
\hline \multirow[t]{3}{*}{ Addet } & ET-TM mod & 0.830 & 1.571 & -1.856 & \multicolumn{2}{|c|}{$0.541(15.1 \%)$} & 0.058 & -0.052 \\
\hline & ET-TM modopt $_{1}$ & 0.830 & 1.434 & -1.658 & \multicolumn{2}{|c|}{$0.449(12.6 \%)$} & 0.352 & 0.029 \\
\hline & $\mathrm{ET}_{\text {nclct }}$ & 0.830 & 1.526 & -1.791 & \multicolumn{2}{|c|}{$0.492(13.8 \%)$} & 0.221 & -0.025 \\
\hline \multirow[t]{3}{*}{ Bahr Dar } & ET-TM $M_{\text {mod }}$ & 0.805 & 1.346 & -1.032 & \multicolumn{2}{|c|}{$0.530(14.4 \%)$} & 0.292 & -0.066 \\
\hline & ET-TM modopt $_{\text {t }}$ & 0.805 & 1.259 & -0.939 & \multicolumn{2}{|c|}{$0.423(11.5 \%)$} & 0.548 & -0.004 \\
\hline & $\mathrm{ET}_{\text {nclct }}$ & 0.805 & 1.273 & -0.954 & \multicolumn{2}{|c|}{$0.434(11.8 \%)$} & 0.525 & -0.014 \\
\hline Dangla & ET-TM $M_{\text {mod }}$ & 0.639 & 1.110 & -0.037 & 0.660 & & 0.032 & -0.099 \\
\hline & ET-TM modopt $_{1}$ & 0.638 & 0.973 & 0.016 & 0.498 & $.5 \%)$ & 0.449 & 0.021 \\
\hline & $\mathrm{ET}_{\text {nclct }}$ & 0.638 & 1.070 & -0.0211 & 0.585 & $.9 \%)$ & 0.239 & -0.064 \\
\hline Debre Birhan & ET-TM mod $_{\text {m }}$ & 0.813 & 0.909 & -0.107 & 0.487 & $.9 \%)$ & 0.368 & 0.124 \\
\hline & ET-TM modopt $_{1}$ & 0.813 & 1.041 & -0.173 & 0.310 & 5\%) & 0.744 & 0.013 \\
\hline & $\mathrm{ET}_{\text {nclct }}$ & 0.813 & 0.966 & -0.135 & 0.376 & $.5 \%)$ & 0.624 & 0.075 \\
\hline Desse & ET-TM $M_{\text {mod }}$ & 0.788 & 1.029 & -0.406 & 0.413 & $.5 \%)$ & 0.399 & 0.083 \\
\hline & ET-TM modopt $_{1}$ & 0.788 & 1.121 & -0.475 & 0.315 & 3\%) & 0.642 & 0.013 \\
\hline & $\mathrm{ET}_{\text {nclct }}$ & 0.788 & 1.074 & -0.439 & 0.346 & 5\%) & 0.579 & 0.048 \\
\hline Mekele & ET-TM $M_{\text {mod }}$ & 0.815 & 0.818 & 0.592 & 0.334 & 2\%) & 0.768 & 0.037 \\
\hline & ET-TM modopt $_{1}$ & 0.814 & 0.852 & 0.599 & 0.300 & 4\%) & 0.813 & 0.001 \\
\hline & $\mathrm{ET}_{\text {nclct }}$ & 0.215 & 0.797 & 0.587 & 0.383 & 4\%) & 0.695 & 0.059 \\
\hline Metehara & ET-TM $M_{\text {mod }}$ & 0.788 & 0.871 & 0.353 & 0.364 & 9\%) & 0.681 & 0.047 \\
\hline & ET-TM modopt $_{1}$ & 0.788 & 0.914 & 0.350 & 0.311 & 2\%) & 0.767 & 0.005 \\
\hline & $\mathrm{ET}_{\text {nclct }}$ & 0.788 & 0.901 & 0.350 & 0.317 & 4\%) & 0.757 & 0.018 \\
\hline Station & Model tendency & & & Model perfc & ormance & & & \\
\hline & By CRM & By slope & By 1:1 line & By CE & By $R^{2}$ and b & PB & CV & MPE \\
\hline Addis Ababa & Agreement & OE (5.7\%) & Slight OE & $\mathrm{S}$ & $\mathrm{G}$ and $\mathrm{G}$ & All in & 18.1 & 7.0 \\
\hline & Agreement & $\mathrm{OE}(3.8 \%)$ & Slight UE & $\mathrm{S}$ & $\mathrm{G}$ and $\mathrm{G}$ & All in & 18.0 & 7.0 \\
\hline & Slight UE & $\mathrm{OE}(1.6 \%)$ & Slight UE & $S$ & $\mathrm{G}$ and $\mathrm{G}$ & All in & 18.0 & 7.3 \\
\hline Addet & Slight OE & $\mathrm{OE}(57.1 \%)$ & Mixed & $\mathrm{BP}$ & $\mathrm{G}$ and $\mathrm{P}$ & Most in & 25.71 & 11.17 \\
\hline & Slight UE & $\mathrm{OE}(43.4 \%)$ & Mixed & $\mathrm{S}$ & $G$ and $P$ & Most in & 25.45 & 12.18 \\
\hline & Slight OE & $\mathrm{OE}(52.6 \%)$ & Mixed & $P$ & $G$ and $P$ & Most in & 25.62 & 11.26 \\
\hline Bahr Dar & Slight OE & UE (34.6\%) & Mixed & $\mathrm{P}$ & $\mathrm{G}$ and $\mathrm{P}$ & Most in & 24.10 & 10.53 \\
\hline & Agreement & UE (25.9\%) & Mixed & $S$ & $\mathrm{G}$ and $\mathrm{G}$ & All in & 23.93 & 9.52 \\
\hline & Slight OE & UE (27.3\%) & Mixed & $\mathrm{S}$ & $\mathrm{G}$ and $\mathrm{G}$ & All in & 23.96 & 9.54 \\
\hline Dangla & Slight OE & OE (11\%) & $\mathrm{OE}$ & $\mathrm{BP}$ & $\mathrm{G}$ and $\mathrm{G}$ & One out & 25.01 & 13.43 \\
\hline & Slight UE & $\mathrm{OE}(2.7 \%)$ & Slight OE & $\mathrm{S}$ & $\mathrm{G}$ and $\mathrm{G}$ & All in & 24.66 & 13.63 \\
\hline & Slight OE & $\mathrm{OE}(7.0 \%)$ & Slight OE & $\mathrm{P}$ & $\mathrm{G}$ and $\mathrm{G}$ & All in & 24.92 & 13.02 \\
\hline Debre Birhan & $\mathrm{OE}$ & UE (9.1\%) & UE & $S$ & $\mathrm{G}$ and $\mathrm{G}$ & All in & 21.69 & 15.55 \\
\hline & Slight OE & $\mathrm{OE}(4.1 \%)$ & Overlap & $\mathrm{S}$ & $\mathrm{G}$ and $\mathrm{G}$ & All in & 22.04 & 7.47 \\
\hline & Slight OE & UE (3.4\%) & UE & $\mathrm{S}$ & $\mathrm{G}$ and $\mathrm{G}$ & All in & 21.84 & 10.57 \\
\hline Desse & Slight UE & OE (2.9\%) & UE & $\mathrm{S}$ & $\mathrm{G}$ and $\mathrm{G}$ & Most in & 18.86 & 11.36 \\
\hline & Slight UE & $\mathrm{OE}(12.1 \%)$ & Slight OE & $\mathrm{S}$ & $\mathrm{G}$ and $\mathrm{G}$ & All in & 19.05 & 7.57 \\
\hline & Slight UE & $\mathrm{OE}(7.4 \%)$ & Slight UE & $S$ & $\mathrm{G}$ and $\mathrm{G}$ & All in & 18.95 & 8.87 \\
\hline Mekele & Slight UE & $\mathrm{OE}(18.2 \%)$ & UE & G & $\mathrm{G}$ and $\mathrm{G}$ & All in & 16.07 & 6.69 \\
\hline & Agreement & $\mathrm{OE}(14.8 \%)$ & Slight UE & G & G and G & All in & 16.14 & 5.73 \\
\hline & Slight UE & UE (20.3\%) & UE & $S$ & $\mathrm{G}$ and $\mathrm{G}$ & All in & 16.02 & 7.93 \\
\hline
\end{tabular}


Table 8 (continued)

\begin{tabular}{|c|c|c|c|c|c|c|c|c|}
\hline \multirow[t]{2}{*}{ Station } & \multicolumn{3}{|c|}{ Model tendency } & \multicolumn{5}{|c|}{ Model performance } \\
\hline & By CRM & By slope & By $1: 1$ line & By CE & By $R^{2}$ and $b$ & PB & $\mathrm{CV}$ & MPE \\
\hline \multirow[t]{3}{*}{ Metehara } & Slight UE & OE (12.9\%) & UE & $\mathrm{S}$ & G and $G$ & All in & 15.49 & 7.19 \\
\hline & Agreement & OE (8.6\%) & Slight UE & G & $\mathrm{G}$ and $\mathrm{G}$ & All in & 15.58 & 5.83 \\
\hline & Slight UE & OE (9.9\%) & Slight UE & G & $\mathrm{G}$ and $\mathrm{G}$ & All in & 15.55 & 6.06 \\
\hline
\end{tabular}

Table 9 Performance comparisons of the three methods

\begin{tabular}{|c|c|c|c|c|c|c|}
\hline \multirow[t]{2}{*}{ Method } & \multirow{2}{*}{$\begin{array}{l}\text { Percent difference } \\
\text { by slope }\end{array}$} & \multicolumn{2}{|l|}{ CE } & \multicolumn{2}{|c|}{$R^{2}$ and slope } & \multirow[t]{2}{*}{ MPE } \\
\hline & & Gor $\mathrm{S}$ & $\mathrm{P}$ & G or S & $\mathrm{P}$ & \\
\hline ET-TM mod $_{\text {m }}$ & $0.8-12.3$ & 5 & 3 & 8 & 0 & $6.7-15.6$ \\
\hline ET-TM modopt $_{\text {mo }}$ & $0.5-2.3$ & 8 & 0 & 8 & 0 & $5.7-13.6$ \\
\hline $\mathrm{ET}_{\text {nclct }}$ & $1.7-7.4$ & 6 & 2 & 8 & 0 & $6.1-13.0$ \\
\hline
\end{tabular}

$\mathrm{G}$ or $\mathrm{S}=$ good or satisfactory; $\mathrm{P}=$ poor. The corresponding numbers indicate the number of stations
Table 10 Altitude, latitude and averaged maximum temperatures of the two test stations

\begin{tabular}{llllll}
\hline Station & Altitude $(\mathrm{m})$ & Latitude $\left({ }^{\circ}\right)$ & $\bar{T}_{\mathrm{mx}}\left({ }^{\circ} \mathrm{C}\right)$ & $(\mathrm{A})(\varphi) /\left(T_{\mathrm{mx}}\right)$ & $n_{\text {clct }}$ \\
\hline Zeway & 1640 & 7.56 & 26.86 & 89.065 & 2.494 \\
Hawassa & 1680 & 6.62 & 27.12 & 78.747 & 2.498 \\
\hline
\end{tabular}

the monthly averaged data was considered as compared to those of Hawassa station.

From among the temperature-based ET estimation methods, Blaney-Criddle, Priestley-Taylor and Thornthwaite methods incorporate latitude [21] but not in explicit forms. Lincare explicitly used altitude (in the form of temperature adjusted for elevation) and latitude [17]. In Lincare equation, the two parameters were not used in product form but in the form of rational function. The equation, besides being more complex than the equation we formulated in this study (Eq. 10), requires two limitations for its application. Its first limitation is the requirement of precipitation of at least $5 \mathrm{~mm}$ per month and the second, mean dew point depression of at least $4{ }^{\circ} \mathrm{C}$ [17]. The two limitations reduce applicability of the Lincare method except in areas where the limitations are satisfied. In addition, the Lincare method requires two more parameters (relative humidity and wind speed), which are not readily available in some remote stations. Thus, the use of modified and calibrated Melesse equation seems a better alternative as it has no limitations, and above all, since it has only variable, $T_{\mathrm{mx}}$.

\section{Conclusion}

In this study, three different methods of estimating the maximum temperature power $(n)$ in TM equation were tested. In order to obtain ' $n$ ' using data that satisfy PM equation, two types of calibration methods were tested. The first calibration was made using monthly averaged data points that spans from 1 to 5 years. In the second method, daily data that span from 10 to 30 days were used. For stations that do not have data that satisfy PM equation, the third method of estimating ' $n$ ' from location latitude, altitude and mean of monthly averaged maximum temperature of the area was used.

As far as the test results are concerned, calibration using the monthly data worked very well with no differences in the number of years considered, which means 12-month data are sufficient for calibration. The daily data calibration managed to give satisfactory ' $n$ ' values for all the stations considered, but the statistical parameters and the performance tests were not as good as the monthly averaged results. Hence, calibration using daily data is not recommended and should only be used as a last option. Estimation of ' $n$ ' from latitude, altitude and the mean of the monthly averaged maximum temperature value worked well for all the stations. In seven out the eight stations, it outperformed the modified ET-TM. But its performance was slightly limited when daily data were used instead of the monthly averaged data. 


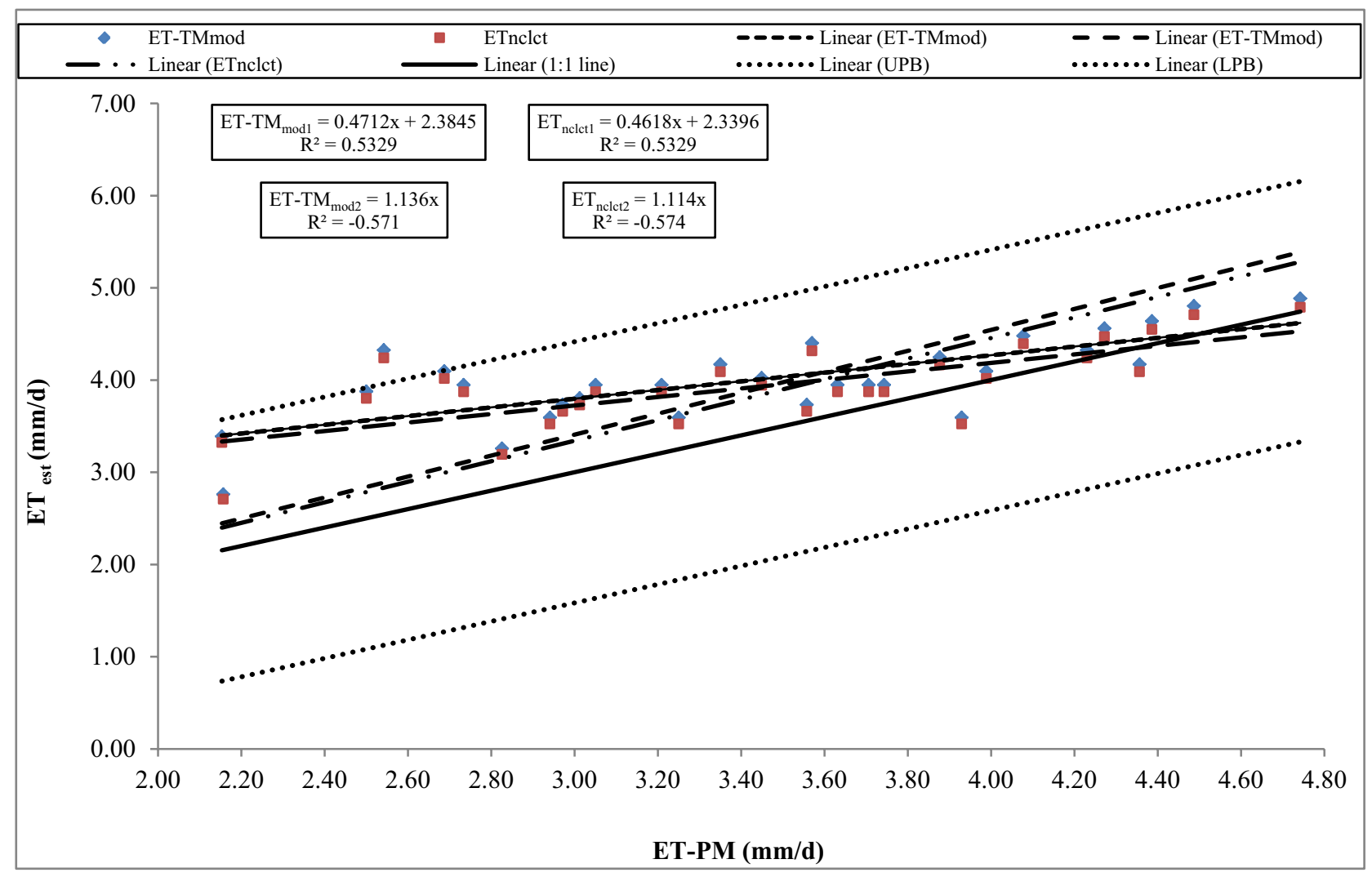

(Hawassa)

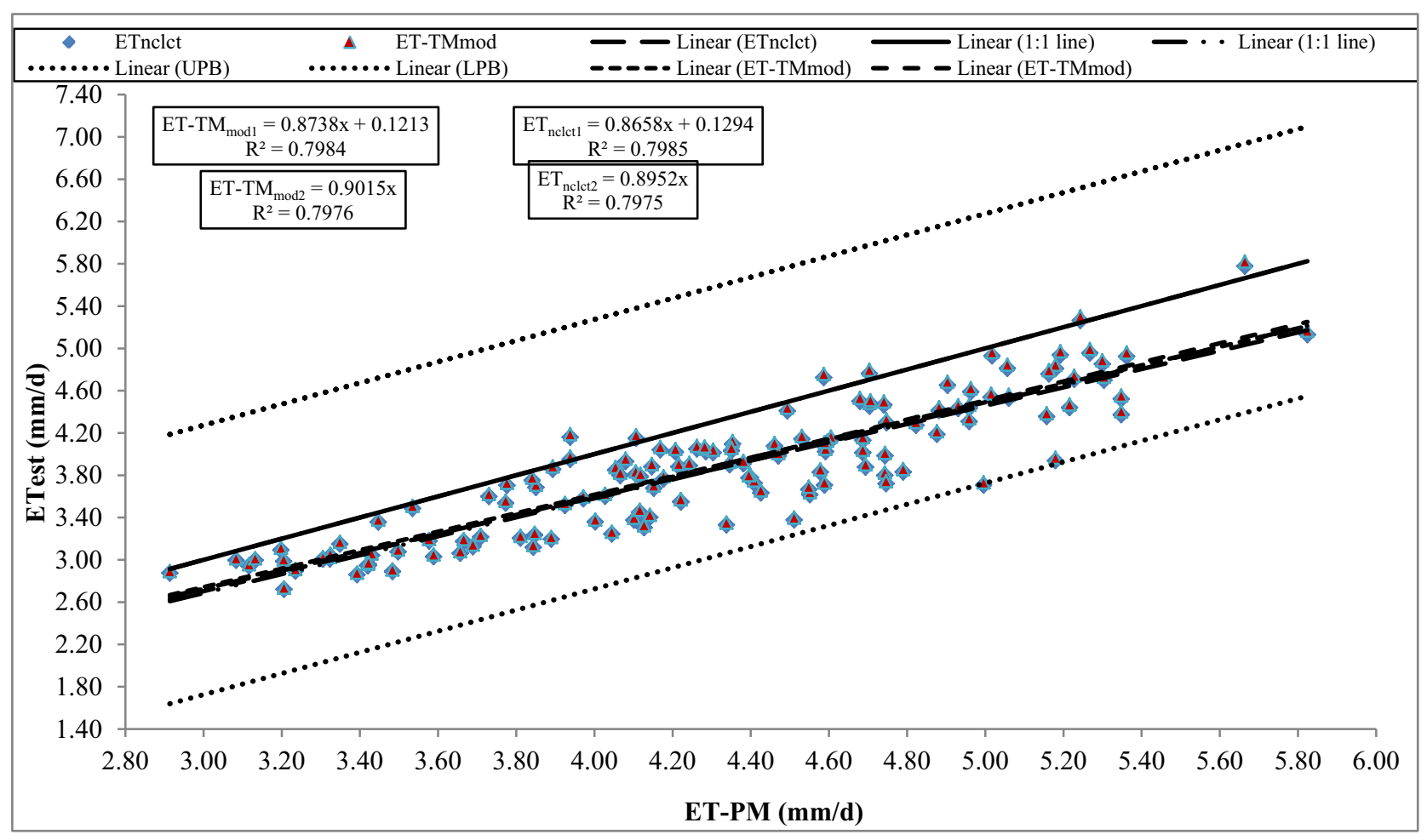

(Zeway)

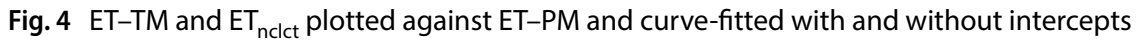


Table 11 Summarized results of test statistics and performance tests of the two methods

\begin{tabular}{|c|c|c|c|c|c|c|c|}
\hline \multirow[t]{2}{*}{ Test station } & \multirow[t]{2}{*}{ Method } & \multirow[t]{2}{*}{$R^{2}$} & \multirow[t]{2}{*}{ Slope } & \multirow[t]{2}{*}{ Intercept } & \multicolumn{3}{|c|}{ Performance test } \\
\hline & & & & & 1:1 line & $R^{2}$ and slope & PB \\
\hline \multirow[t]{4}{*}{ Hawassa } & ET-TM $\bmod 1$ & 0.5329 & 0.4712 & 2.3845 & $\mathrm{OE}$ & $\mathrm{S}$ and $\mathrm{P}$ & Most in \\
\hline & ET-TM mod2 $_{2}$ & 0.5710 & 1.136 & - & $\mathrm{OE}$ & S and $G$ & \\
\hline & $\mathrm{ET}_{\text {nclct1 }}$ & 0.5329 & 0.4618 & 2.3896 & $\mathrm{OE}$ & $S$ and $P$ & Most in \\
\hline & $\mathrm{ET}_{\text {nclct2 }}$ & 0.5740 & 1.114 & & $\mathrm{OE}$ & S and $G$ & \\
\hline \multirow[t]{4}{*}{ Zeway } & ET-TM mod $1_{1}$ & 0.7984 & 0.8738 & 0.1213 & UE & $\mathrm{G}$ and $\mathrm{G}$ & All in \\
\hline & ET-TM mod2 $_{\text {mat }}$ & 0.7976 & 0.9015 & & UE & $\mathrm{G}$ and $\mathrm{G}$ & \\
\hline & $\mathrm{ET}_{\text {nclct1 }}$ & 0.7985 & 0.8658 & 0.1294 & UE & G and $G$ & All in \\
\hline & $\mathrm{ET}_{\text {nclct2 }}$ & 0.7975 & 0.8952 & & UE & G and $G$ & \\
\hline
\end{tabular}

$S$ and $G$ stand for satisfactory and good

$O E$ overestimation, UE underestimation, $P B$ prediction bound

\section{Compliance with ethical standards}

Conflict of interest The author(s) declare that they have no conflict of interests.

\section{References}

1. Aguilar C, Polo MJ (2011) Generating reference evapotranspiration surfaces from the Hargreaves equation at watershed scale. Hydrol Earth Syst Sci 15:2495-2508

2. Alblewi B (2012) Assessment of evapotranspiration models under hyper-arid environments. M.Sc. Thesis, University of Guelph, Ontario, Canada

3. Allen RG, Pereira LS, Raes D, Smith M (1998) Crop ET guidelines for computing crop water requirements. FAO irrigation and drainage paper no. 56. Rome, Italy

4. Allen RG, Pereira LS, Raes D, Smith M (2006) FAO irrigation and drainage paper no. 56. Rome, Italy

5. Almorox J, Quej VH, Martí P (2015) Global performance ranking of temperature-based approaches for evapotranspiration estimation considering Köppen climate classes. J Hydrol 528:514-522

6. ASCE Environmental and Water Resources Institute (ASCE-EWRI) (2005) ASCE standardized reference evapotranspiration equation. Standardization of reference evapotranspiration task committee final report, Reston, VA, 59

7. Bogawski P, Bednorz E (2014) Comparison and validation of selected evapotranspiration models for conditions in Poland (Central Europe). Water Resour Manag 28:5021-5038. https:// doi.org/10.1007/s11269-014-0787-8

8. Da Silva Junior RO, De Souza EB, Tavares AL, Mota JA, Ferreira DBS, Souza-Filho PWM, Da Rocha EJP (2017) Three decades of reference evapotranspiration estimates for a tropical watershed in the eastern Amazon. Ann Braz Acad Sci 89(3 Suppl.):1985-2002

9. Dinpashoh Y (2006) Study of reference crop evapotranspiration in IR of Iran. Agric Water Manag 84(1-2):123-129

10. Edebeatu CC (2015) Comparison of four empirical evapotranspiration models against Penman-Monteith in a mangrove zone. Int J Appl Sci Eng Res 4(4):580-589

11. Fernandes LC, Paiva CM, Filho OCR (2012) Evaluation of six empirical evapotranspiration equations-case study of Campos Dos Goytacazes/RJ. Rev Bras Meteorol 27(3):272-280
12. Hupet $F$, Vanclooster $M$ (2001) Effect of the sampling frequency of meteorological variables on the estimation of the reference evapotranspiration. J Hydrol 243(3-4):192-204

13. Ilesanmi OA (2014) Evaluation of four evapotranspiration models for IITA stations in Ibadan, Onne and Kano, Nigeria. J Environ Earth Sci 4(5):89-97

14. Jensen DT, Hargreaves GH, Temesgen B, Allen RG (1997) Computation of evapotranspiration under non-ideal conditions. J Irrig Drain Eng 123:394-400

15. Lang D, Zheng J, Shi J, Liao F, Ma X, Wang W, Chen X, Zhang M (2017) A comparative study of potential evapotranspiration estimation by eight methods with FAO Penman-Monteith method in southwestern China. Water 9:734-752. https://doi. org/10.3390/w9100734

16. Martí P, González-Altozano P, López-Urrea R, Manchaamón LA, Shiri J (2015) Modeling reference evapotranspiration with calculated targets. Assessment and implications. Agric Water Manag 149:81-90

17. Maule C, Helgson W, McGiin S, Cutforth H (2006) Estimation of standardized reference evapotranspiration on the Canadian Prairies using simple models with limited weather data. Can Biosyst Eng 48:1.1-1.11

18. Medeiros PV, Marcuzzo FFN, Youlton C, Wendland E (2011) Error autocorrelation and linear regression for temperature-based evapotranspiration estimates improvement. J Am Water Resour Assoc 48(2):1-9

19. Neto AJS, Borges Júnior JCF, Andrade CLT, Lopes DC, Nascimento PT (2015) Reference evapotranspiration estimates based on minimum meteorological variable requirements of historical weather data. Chil J Agric Res 75(3):366-374

20. Oudin L, Moulin L, Bendjoudi H, Ribstein P (2010) Estimating potential evapotranspiration without continuous daily data: possible errors and impact on water balance simulations. Hydrol Sci J 55(2):209-222. https://doi.org/10.1080/026266609035461 18

21. Pandey PK, Dabral PP, Pandey V (2016) Evaluation of reference evapotranspiration methods for the northeaster nregion of India. Int Soil Water Conserv Res 4:52-63

22. Peng L, Li Y, Feng H (2017) The best alternative for estimating reference crop evapotranspiration in different sub-regions of mainland China. Sci Rep 7:5458. https://doi.org/10.1038/s4159 8-017-05660-y

23. Semu A (2010) Developing regional potential evapotranspiration (PET) estimation method for Abbay river basin. J EEA 27:25-33

24. Tegos A, Estratiadis A, Koutsoyiannis D (2013) A parametric model for potential evapotranspiration estimation 
based on a simplified formulation of the Penman-Monteith equation. Intech, open science/open minds. http://dx.doi. org/10.5772/52927

25. Temesgen E, Melesse AM (2013) A simple temperature method for estimation of evapotranspiration. Hydrological processes. Retrieved on 06 June 2016

26. Temesgen B, Allen RG, Jensen DT (1999) Adjusting temperature parameters to reflect well-watered conditions. J Irrig Drain Eng 125(1):26-33

27. Wang Yu-Min, Namaona W, Traore S, Zhang Zhao-Cheng (2009) Seasonal temperature-based models for reference evapotranspiration estimation under semi-arid condition of Malawi. Afr J Agric Res 4(9):878-886

28. Xu CY, Singh VP (2001) Evaluation of generalization of temperature-based methods for calculating evaporation. Hydrol Process 15:305-319
29. Xu CY, Singh VP (2002) Cross comparison of empirical equations for calculating potential evapotranspiration with data from Switzerland. Water Resour Manag 16(3):197-219

30. Xystrakis F, Matzarakis A (2011) Evaluation of 13 empirical reference potential evapotranspiration equations on the Island of Crete in southern Greece. J Irrig Drain Eng 137:211-222

Publisher's Note Springer Nature remains neutral with regard to jurisdictional claims in published maps and institutional affiliations. 